\title{
Ruthenium-Catalyzed Amide-Bond Formation
}

\author{
Pascale Crochet, Victorio Cadierno*
}

Laboratorio de Compuestos Organometálicos y Catálisis (Unidad Asociada al CSIC), Red ORFEO-CINQA - Centro de Innovación en Química Avanzada, Departamento de Química Orgánica e Inorgánica, Instituto Universitario de Química Organometálica “Enrique Moles”, Facultad de Química, Universidad de Oviedo, Julián Clavería 8, E-33006 Oviedo, Spain.E-mail:vcm@uniovi.es

\begin{abstract}
The amide functionality is one of the most important functional groups in organic and biological chemistry. Classical synthetic strategies of amides involve the stoichiometric, and poor atom efficient, reaction of amines with carboxylic acid derivatives. Transition-metal-catalyzed reactions have emerged in recent years as more atom-economical and powerful tools for preparing amides, opening previously unavailable routes from substrates other than the carboxylic acids and their derivatives. Ruthenium-based catalysts have been at the heart of these advances, and this chapter pretends to give an overview of the field. Among others, the following ruthenium-catalyzed synthetic approaches of amides will be discussed: the hydration of nitriles, the hydrolytic amidation of nitriles with amines, the rearrangement of aldoximes, the coupling of aldehydes with hydroxylamine, and the dehydrogenative amidation of alcohols, aldehydes and esters.
\end{abstract}

Keywords Ruthenium catalysts, amide-bond formation, nitrile hydration, hydrolytic amidation, dehydrogenative amidation, rearrangements

$\begin{array}{ll}\text { Abbreviations } & \\ \mathrm{Ac} & \text { acetyl } \\ \mathrm{acac} & \text { acetylacetonate } \\ \mathrm{Bn} & \text { benzyl } \\ n-\mathrm{Bu} & \text { butyl } \\ i \text {-Bu } & i s o \text {-butyl } \\ s-\mathrm{Bu} & \text { sec-butyl } \\ t \text { - } \mathrm{Bu} & \text { tert-butyl } \\ \mathrm{cod} & 1,5 \text {-cyclooctadiene } \\ \mathrm{cot} & 1,3,5,7 \text {-cyclooctatetraene } \\ \mathrm{Cy} & \text { cyclohexyl } \\ \mathrm{Da} & \text { Dalton } \\ \mathrm{DCE} & 1,2 \text {-dichloroethane }\end{array}$




\begin{tabular}{|c|c|}
\hline DFT & density functional theory \\
\hline DME & 1,2-dimethoxyethane \\
\hline DMSO & dimethyl sulfoxide \\
\hline DNA & deoxyribonucleic acid \\
\hline $\mathrm{dppb}$ & 1,4-bis(diphenylphosphino)butane \\
\hline dppe & 1,2-bis(diphenylphosphino)ethane \\
\hline dppm & bis(diphenylphosphino)methane \\
\hline equiv & equivalent(s) \\
\hline $\mathrm{Et}$ & ethyl \\
\hline $\mathrm{h}$ & hour(s) \\
\hline $\mathrm{I} i \mathrm{Pr}$ & 1,3-diisopropylimidazol-2-ylidene \\
\hline $\mathrm{Me}$ & methyl \\
\hline $\min$ & minute(s) \\
\hline mol & mole $(\mathrm{s})$ \\
\hline Ms & mesyl, methanesulfonyl \\
\hline MW & microwave \\
\hline NHC & $N$-heterocyclic carbene \\
\hline NSAIDs & non-steroidal anti-inflammatory drugs \\
\hline $\mathrm{PCyp}_{3}$ & tricyclopentylphosphine \\
\hline Pent & pentyl \\
\hline $\mathrm{Ph}$ & phenyl \\
\hline $\mathrm{PPh}_{2}$ py & 2-(diphenylphosphino)pyridine \\
\hline $\mathrm{PPh}_{2}\left(\mathrm{py}-4-\mathrm{NMe}_{2}\right)$ & 2-diphenylphosphino-4-pyridyl(dimethyl)amine \\
\hline $\operatorname{Pr}$ & propyl \\
\hline$i-\operatorname{Pr}$ & iso-propyl \\
\hline PTA & 1,3,5-triaza-7-phosphaadamantane \\
\hline PVP & polyvinylpyrrolidone \\
\hline py & pyridine \\
\hline $\mathrm{rt}$ & room temperature \\
\hline terpy & $2,2^{\prime}: 6^{\prime}, 2^{\prime \prime}$-terpyridine \\
\hline TOF & turnover frequency \\
\hline TON & turnover number \\
\hline $\mathrm{Tp}$ & hydrotris(pyrazolyl)borate \\
\hline Ts & tosyl, 4-toluenesulfonyl \\
\hline
\end{tabular}

\section{Introduction}

The amide bond is one of the most important linkages in organic chemistry, and also plays a major role in the composition of biological systems since it constitutes a leit motiv unit in the structure of peptides and proteins. Amides are versatile synthetic intermediates used in the manufacture of several pharmacological and biological active products, polymers, detergents, lubricants and drug stabilizers. They 
are also key structural motifs in multitude of natural products [1,2]. Studies carried out by leading pharmaceutical companies have pointed out that amide bond forming reactions are among the most executed chemical transformations in their laboratories $[3,4]$. Indeed, an in-depth analysis of medicinal chemistry databases revealed that the amide group is present in more than $25 \%$ of the drugs currently known [5]. All these facts clearly show the importance and prevalence of amides in synthetic organic chemistry.

In general, traditional approaches for amide synthesis rely on the use of activated carboxylic acid derivatives and amines, processes which often require stoichiometric amounts of coupling reagents and suffer from the inherent drawback of producing large amounts of waste products along with the desired amide $[1,2,6,7]$. In this sense, a recent report by the ACS GCIPR (American Chemical Society Green Chemistry Institute Pharmaceutical Roundtable) has identified amide formation avoiding poor atom economy reagents as a priority area of research for the pharmaceutical industry [8]. In the search of improved synthetic methods, metalcatalyzed transformations have emerged in recent years as the most promising alternatives for the atom-economical and cost effective synthesis of amides. The use of metal catalysts has also opened previously unavailable routes starting from substrates other than carboxylic acids and their derivatives [9-14]. Ruthenium-based catalysts have been at the heart of these recent advances and, herein, an overview of the ruthenium-catalyzed amide bond forming reactions reported to date in the literature is presented. Both homogeneous and heterogeneous systems will be discussed. Transformations in which the amide functionality already exists in the molecule, and a ruthenium catalyst is employed to promote further structural modifications, are considered to be out of the scope of this chapter.

\section{Ruthenium-Catalyzed Hydration of Nitriles}

Addition of water to the $\mathrm{C} \equiv \mathrm{N}$ bond of nitriles is probably the simplest route that one can imagine to generate primary amides in an atom economical manner. This reaction is currently employed in industry for the large-scale production of acrylamide, nicotinamide, 5-cyanovaleramide and the antiepileptic drug levetiracetam through biocatalytic transformations [15-18]. More conventional methods to hydrate nitriles involve the use of strong acids and bases under harsh conditions. However, these classical methods are not compatible with many functional groups, and they are usually unable to control hydrolysis to the corresponding carboxylic acids (Scheme 1) or the competing formation of polymeric side products [19]. Transition-metal complexes are able to facilitate the hydration reaction by activating the nitrile substrate, the water nucleophile, or both upon coordination. Accordingly, a variety of metal catalysts, showing a high selectivity towards the amide under milder conditions to those employed with strong acids or bases, have been described in the literature [20-22]. In this context, 
ruthenium complexes are among the most versatile nitrile hydration catalysts discovered with regard to activity, selectivity and tolerance to functional groups.

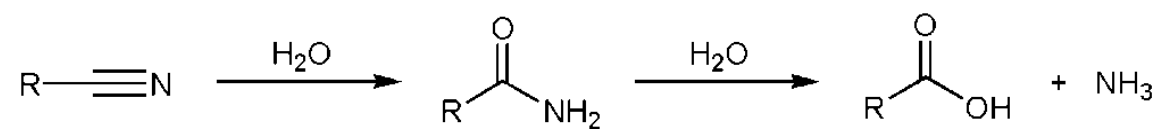

Scheme 1. The nitrile hydration and amide hydrolysis reactions.

Pioneering work in the field was reported by Murahashi and co-workers in 1992 employing the ruthenium(II)-dihydride complex $\left[\mathrm{RuH}_{2}\left(\mathrm{PPh}_{3}\right)_{4}\right]$ [23-26]. Hydration of several organonitriles proceeded smoothly with $3 \mathrm{~mol} \%$ of $\left[\mathrm{RuH}_{2}\left(\mathrm{PPh}_{3}\right)_{4}\right]$ upon treatment with 1-2 equivalents of water in DME at $120^{\circ} \mathrm{C}$, leading to the corresponding primary amides in high yields (TOF up to $2 \mathrm{~h}^{-1}$ ). A catalytic cycle involving the initial coordination of the nitrile to ruthenium, followed by intermolecular nucleophilic attack of water to generate an iminol that tautomerizes into the amide, was proposed (Scheme 2) [24].

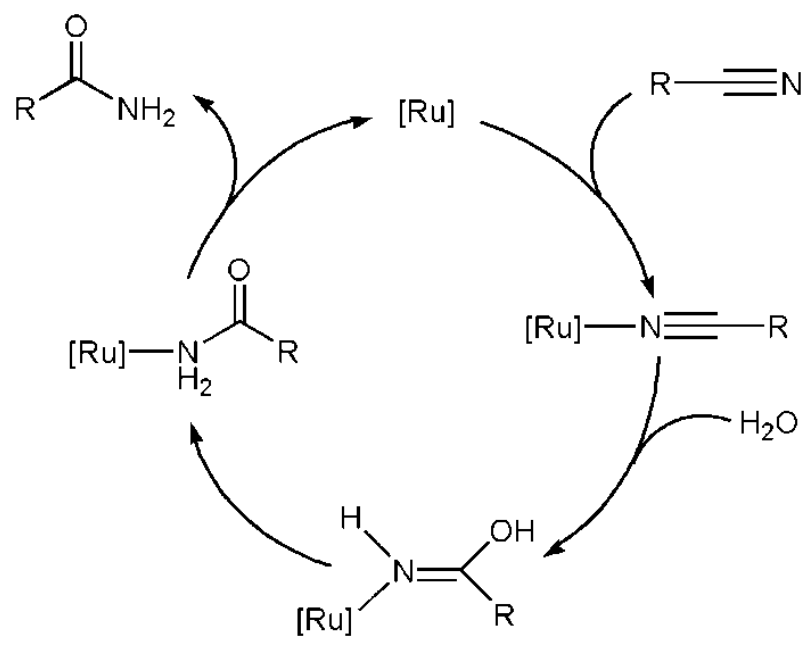

Scheme 2. Catalytic cycle for the hydration of nitriles promoted by $\left[\mathrm{RuH}_{2}\left(\mathrm{PPh}_{3}\right)_{4}\right]$.

As shown in Scheme 3, when $\delta$-keto nitriles were used as the starting materials ene-lactams were selectively formed, via a ruthenium-catalyzed tandem hydration/cyclocondensation sequence $[23,24]$. Such a process was applied by $\mathrm{Mu}-$ rahashi and co-workers in the total synthesis of (-)-pumiliotoxin $\mathrm{C}$, a naturally occurring alkaloid [24]. 


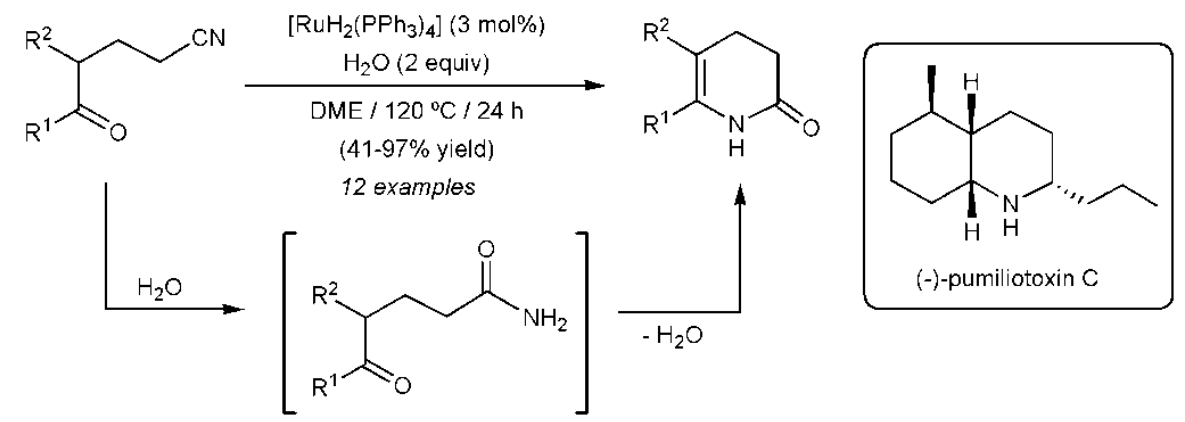

Scheme 3. Catalytic synthesis of ene-lactams using $\left[\mathrm{RuH}_{2}\left(\mathrm{PPh}_{3}\right)_{4}\right]$ and structure of the alkaloid (-)-pumiliotoxin C.

In addition to $\left[\mathrm{RuH}_{2}\left(\mathrm{PPh}_{3}\right)_{4}\right]$, other hydrido-ruthenium(II) complexes $\left[\mathrm{RuH}\left(\eta^{5}\right.\right.$ $\left.\left.\mathrm{C}_{9} \mathrm{H}_{7}\right)(\mathrm{dppm})\right]$ [27], [RuH(Tp) $\left.\left(\mathrm{PPh}_{3}\right)(\mathrm{NCMe})\right]$ [28,29], [RuH $\left.\left\{\mathrm{tmeP} \mathrm{P}_{2} \mathrm{~N}(\mathrm{NH})\right\}\right](\mathbf{1}$ in Figure 1) [30] and $\left[\left\{\left(\mathrm{PCy}_{3}\right)(\mathrm{CO}) \mathrm{RuH}\right\}_{4}\left(\mu_{4}-\mathrm{O}\right)\left(\mu_{3}-\mathrm{OH}\right)\left(\mu_{2}-\mathrm{OH}\right)\right](2$ in Figure 1) [31] proved to be also able to promote the selective hydration of nitriles to primary amides. Among them, the indenyl derivative $\left[\mathrm{RuH}\left(\eta^{5}-\mathrm{C}_{9} \mathrm{H}_{7}\right)(\mathrm{dppm})\right]$ merits to be highlighted since it is able to operate directly in water at relatively high rates [27]. For example, TOF and TON values of $11 \mathrm{~h}^{-1}$ and 800 , respectively, were reached in the hydration of benzonitrile with $0.1 \mathrm{~mol} \%$ of $\left[\mathrm{RuH}\left(\eta^{5}-\mathrm{C}_{9} \mathrm{H}_{7}\right)(\mathrm{dppm})\right]$ at 120 ${ }^{\circ} \mathrm{C}$. This hydrido-ruthenium(II) complex is also interesting from a mechanistic point of view, because it belongs to a particular class of catalysts that activate the nucleophilic water molecule through an outer sphere mechanism. Thus, DFT calculations confirmed that, in the rate-limiting step of the reaction, the nucleophilic attack of water on the coordinated nitrile is assisted by the hydride ligand, which activates the water molecule through a $\mathrm{Ru}-\mathrm{H} \cdots \mathrm{H}-\mathrm{OH}$ hydrogen-bond interaction (Scheme 4).
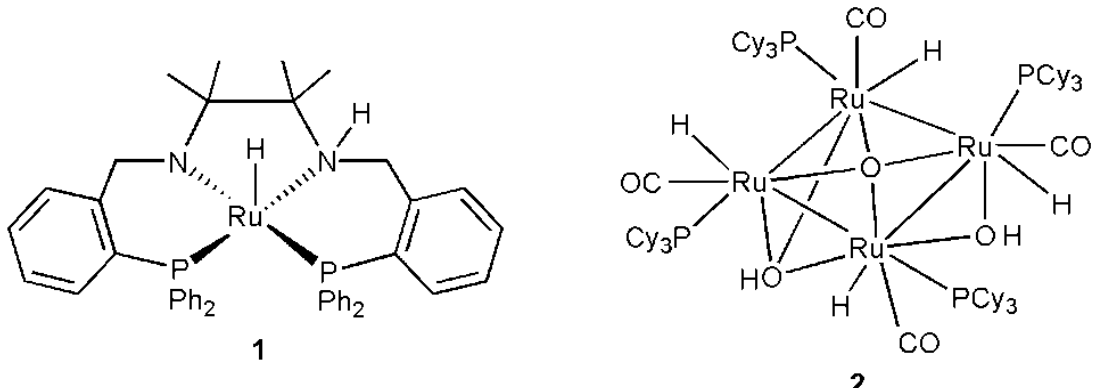

Figure 1. Structure of the hydrido-ruthenium(II) catalysts 1-2. 


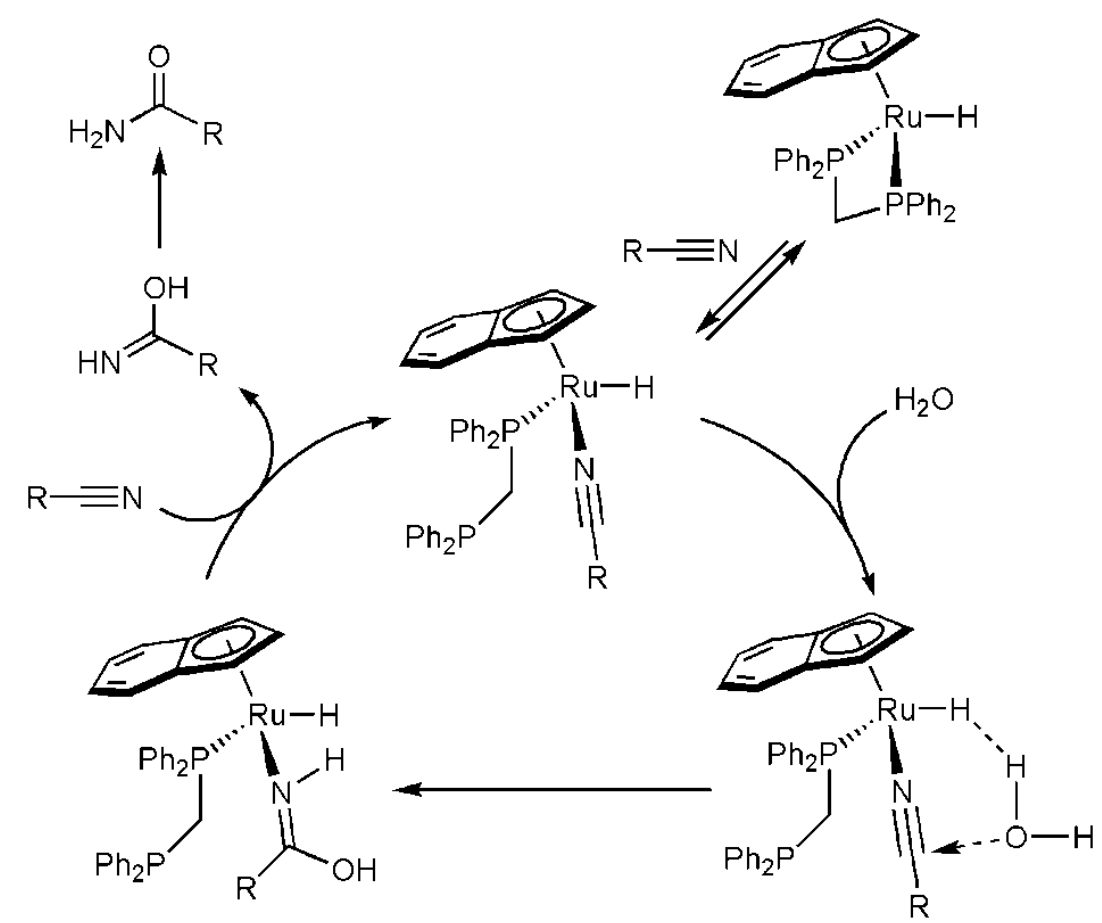

Scheme 4. Catalytic cycle for the hydration of nitriles promoted by $\left[\mathrm{RuH}\left(\eta^{5}-\mathrm{C}_{9} \mathrm{H}_{7}\right)(\mathrm{dppm})\right]$.

A related intramolecular activation of water by the pyridinic nitrogen of the auxiliary 2-(diphenylphosphino)pyridine ligand was proposed by Oshiki and coworkers to explain the high reactivity shown by the octahedral ruthenium(II) complex cis-[Ru(acac $\left.)_{2}\left(\mathrm{PPh}_{2} \mathrm{py}\right)_{2}\right]$ [32-34]. As shown in Scheme 5, performing the reactions in DME at $180{ }^{\circ} \mathrm{C}$ with a small amount of water, this catalyst (0.2-0.4 $\mathrm{mol} \%$ ) was able to transform a large variety of nitriles into the corresponding amides in high yields and short times. An impressive TOF value of $20900 \mathrm{~h}^{-1}$, the highest reported to date for this catalytic transformation, could be reached in the hydration of benzonitrile employing $0.024 \mathrm{~mol} \%$ of cis-[Ru(acac $\left.)_{2}\left(\mathrm{PPh}_{2} \mathrm{py}\right)_{2}\right]$ ( $85 \%$ conversion after $10 \mathrm{~min})$. The cooperative effect exerted by the pyridylphosphine ligand in cis- $\left[\mathrm{Ru}(\mathrm{acac})_{2}\left(\mathrm{PPh}_{2} \mathrm{py}\right)_{2}\right]$ was supported by the fact that replacement of $\mathrm{PPh}_{2}$ py by $\mathrm{PPh}_{3}, \mathrm{PMe}_{3}$ or $\mathrm{P}(n-\mathrm{Bu})_{3}$ led to much less active catalysts [32-34]. The same group also described the hydration of several organonitriles under milder reaction conditions, i.e. in $\mathrm{DME}$ at $80{ }^{\circ} \mathrm{C}$, employing the bis(allyl)ruthenium(II) complex $\left[\mathrm{Ru}\left(\eta^{3}-2-\mathrm{C}_{3} \mathrm{H}_{4} \mathrm{Me}\right)_{2}(\mathrm{cod})\right](0.5 \mathrm{~mol} \%)$ in combination with the dimethylamino-substituted pyridyl-phosphine $\mathrm{PPh}_{2}\left(\mathrm{py}-4-\mathrm{NMe}_{2}\right)(1.5 \mathrm{~mol} \%)$ $[35,36]$. However, we must note that longer reaction times ( $48 \mathrm{~h}$; TOF up to $5 \mathrm{~h}^{-1}$ ) were in this case needed to generate the amides in high yields, and that incomplete 
conversions were in some cases observed. Inspired by these works, other groups have studied the catalytic behaviour of different ruthenium(II) and ruthenium(IV) complexes bearing pyridyl-phosphine ligands, but none of the described systems enabled to improve the results obtained by Oshiki [37,38]. The tendency of the ligands to adopt a chelating coordination was, in some cases, responsible of the low catalytic activity observed [38].
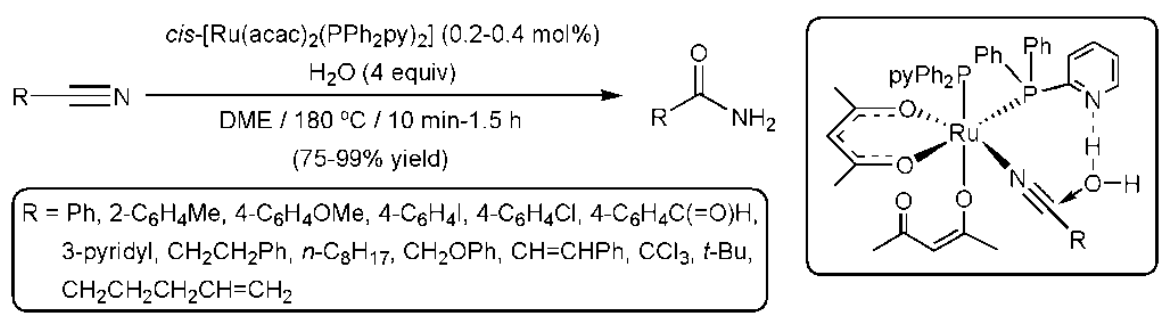

Scheme 5. Catalytic hydration of nitriles using cis-[Ru(acac $\left.)_{2}\left(\operatorname{PPh}_{2} \mathrm{py}\right)_{2}\right]$.

Activation of water by the ancillary phosphine ligands was also evidenced when arene-ruthenium(II) complexes of general composition $\left[\mathrm{RuCl}_{2}\left(\square^{6}\right.\right.$ arene) $\left.\left(\mathrm{Ph}_{2} \mathrm{PC}_{6} \mathrm{H}_{4} \mathrm{CH}_{2} \mathrm{NHR}\right)\right]$ (3 in Figure 2) were employed as catalysts [39].

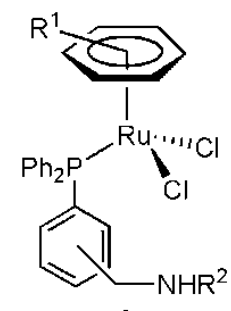

arene $=\mathrm{C}_{6} \mathrm{H}_{6}, p$-cymene, $1,3,5-\mathrm{C}_{6} \mathrm{H}_{3} \mathrm{Me}_{3}, \mathrm{C}_{6} \mathrm{Me}_{6}$

$0-, m$ - and $p$-substituted phosphines

$\mathrm{R}^{2}=i-\mathrm{Pr}, t-\mathrm{Bu}$ (all combinations)

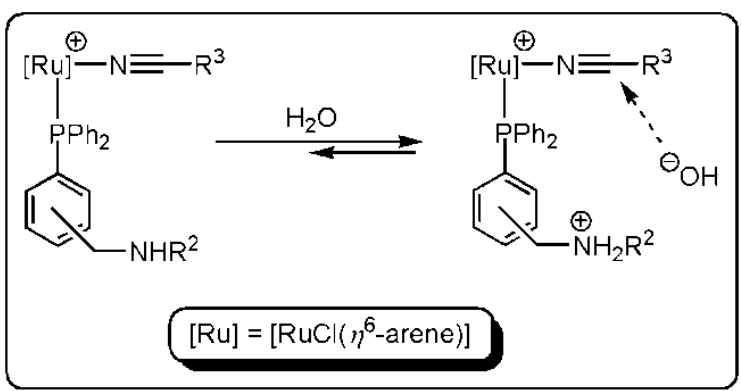

Figure 2. Structure and activating effect of the arene-ruthenium(II) complexes $\left[\operatorname{RuCl}_{2}\left(\eta^{6}-\right.\right.$ arene) $\left.\left(\mathrm{Ph}_{2} \mathrm{PC}_{6} \mathrm{H}_{4} \mathrm{CH}_{2} \mathrm{NHR}\right)\right]$ (3). 
Although the activity shown by these complexes was only moderate (TOF up to 3 $\mathrm{h}^{-1}$ at $100{ }^{\circ} \mathrm{C}$ ), the hydration reactions proceeded significantly faster than those using the analogous triphenylphosphine derivatives $\left[\mathrm{RuCl}_{2}\left(\eta^{6}\right.\right.$-arene $\left.)\left(\mathrm{PPh}_{3}\right)\right]$ under identical experimental conditions (TOF up to $0.1 \mathrm{~h}^{-1}$ ). However, when free amine $\mathrm{PhCH}_{2} \mathrm{NHR}(\mathrm{R}=n$-Bu or $i$-Pr $)$ was added to the $\left[\mathrm{RuCl}_{2}\left(\eta^{6}\right.\right.$-arene $\left.)\left(\mathrm{PPh}_{3}\right)\right]$ catalyzed reactions the hydration rates increased, becoming similar to those observed with complexes 3 [39]. This fact suggested that the higher activity of $\left[\mathrm{RuCl}_{2}\left(\eta^{6}\right.\right.$-arene) $\left.\left(\mathrm{Ph}_{2} \mathrm{PC}_{6} \mathrm{H}_{4} \mathrm{CH}_{2} \mathrm{NHR}\right)\right](3) v s\left[\mathrm{RuCl}_{2}\left(\eta^{6}\right.\right.$-arene $\left.)\left(\mathrm{PPh}_{3}\right)\right]$ is not due to a ligand-assisted activation of water by hydrogen-bonding. More likely, the intrinsic basic nature of the pendant amino group of the aryl-phosphines would increase the concentration of the more nucleophilic hydroxide anion in the solution, thus accelerating the hydration process (Figure 2).

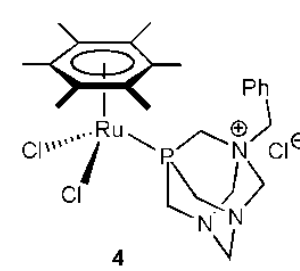

4

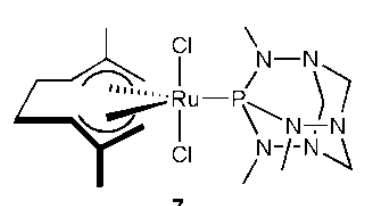

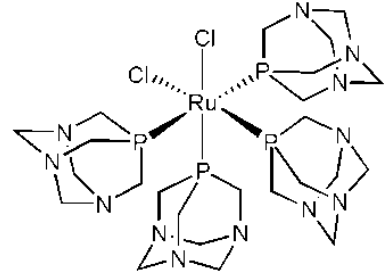

5

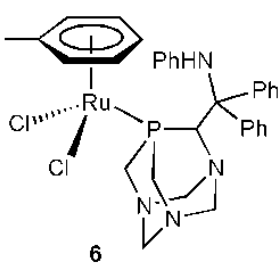

6

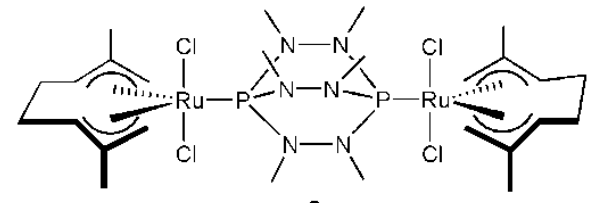

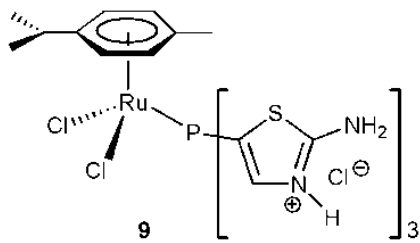

Figure 3. Structure of the water-soluble ruthenium catalysts 4-9.

The use as auxiliary ligands derived from the aminophosphine PTA (1,3,5-triaza7-phosphaadamantane) and related water-soluble "cage-like" phosphines has led in recent years to highly efficient ruthenium catalysts for nitrile hydration in pure water [40-44]. Complexes 4-8 are the most representative examples (Figure 3). Almost quantitative conversions of a wide variety of aromatic, heteroaromatic, $\alpha, \beta$-unsaturated and aliphatic nitriles into the corresponding amides were achieved at $100-150{ }^{\circ} \mathrm{C}$ (classical oil-bath or MW heating) employing $5 \mathrm{~mol} \%$ of these 
complexes (TOF values in the range 30-285 $\mathrm{h}^{-1}$ ). Common functional groups such as halides, nitro, hydroxy, ethers, thioethers, amino, ketones, aldehyde, esters or alkynes were in general tolerated. The high efficiency of 4-8 was attributed to the ability of the nitrogenated phosphines to serve as hydrogen bond acceptors to activate the nucleophilic water molecules. Interestingly, performing the catalytic hydration of benzonitrile with only $0.001 \mathrm{~mol} \%$ of complexes 5 and $\mathbf{6}$ turnover numbers of 22000 and 97000 , respectively, could be attained. However, very long reaction times of 97 (5) [42] and 14 (6) [44] days were needed to achieve such a high productivity. It is also worthy of note that, after selective crystallization of the final amides, recycling of the aqueous phase containing complexes 4 ( 2 times) [40] and 5 (6 times) [42] was possible. The arene-ruthenium(II) complex 9, bearing the water-soluble and potentially H-bond acceptor ligand tris(5-(2aminothiazolyl))-phosphine trihydrochloride (Figure 3), featured also a high activity (TOF up to $66 \mathrm{~h}^{-1}$ ), productivity (TON up to 9800), substrate scope and functional group tolerance, combined with an effective recycling (up to five consecutive runs) [45].
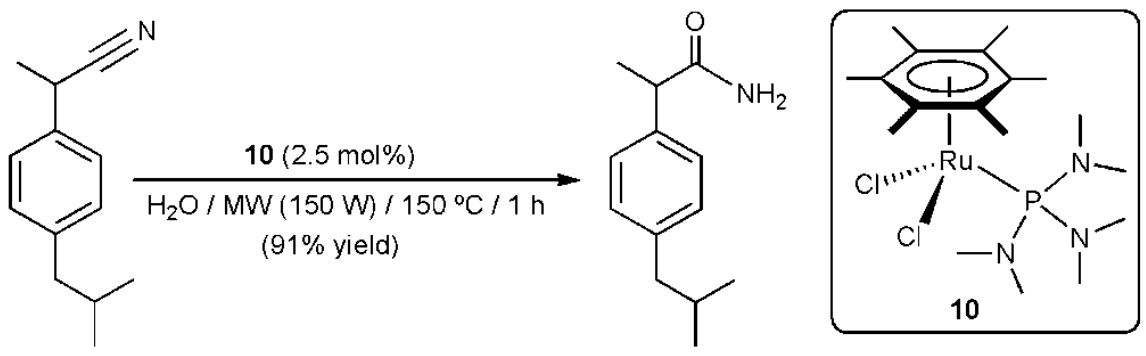<smiles>CC(C#N)c1cccc(C(=O)c2ccccc2)c1</smiles>

Scheme 6. Synthesis of the NSAIDs ibuprofenamide and ketoprofenamide by catalytic hydration.

Selective conversion of nitriles to amides, in water under neutral conditions, was also described employing complexes $\left[\mathrm{RuCl}_{2}\left(\eta^{6}\right.\right.$-arene) $\left.\left\{\mathrm{P}\left(\mathrm{NMe}_{2}\right)_{3}\right\}\right]$ (arene = $\mathrm{C}_{6} \mathrm{H}_{6}, p$-cymene, $\left.1,3,5-\mathrm{C}_{6} \mathrm{H}_{3} \mathrm{Me}_{3}, \mathrm{C}_{6} \mathrm{Me}_{6}\right)$ as catalysts. These compounds make use of the commercially available and inexpensive tris(dimethylamino)phosphine ligand, making them much more attractive for practical applications than the examples discussed above containing rather elaborated water-soluble phosphines. In 
particular, the hexamethylbenzene derivative $\left[\mathrm{RuCl}_{2}\left(\eta^{6}-\mathrm{C}_{6} \mathrm{Me}_{6}\right)\left\{\mathrm{P}\left(\mathrm{NMe}_{2}\right)_{3}\right\}\right]$ (10) proved to be highly efficient, providing the desired amides from a wide range of organonitriles in excellent yields and short times [46,47]. TOF values up to 11400 $\mathrm{h}^{-1}$, the highest reported to date for this catalytic transformation in pure water, were reached with complex 10 by performing the catalytic reactions at $150{ }^{\circ} \mathrm{C}$ under MW irradiation. Remarkably, taking advantage of the outstanding performance of $\left[\mathrm{RuCl}_{2}\left(\eta^{6}-\mathrm{C}_{6} \mathrm{Me}_{6}\right)\left\{\mathrm{P}\left(\mathrm{NMe}_{2}\right)_{3}\right\}\right]$ (10), unprecedented synthetic routes for the preparation of the non-steroidal anti-inflammatory drugs ibuprofenamide and ketoprofenamide, by catalytic hydration of 2-(4-isobutylphenyl)propionitrile and 2-(3-benzoylphenyl)propionitrile, respectively, were developed (Scheme 6) $[46,47]$.

The synthetic utility of complexes $\left[\mathrm{RuCl}_{2}\left(\eta^{6}\right.\right.$-arene $\left.)\left\{\mathrm{P}\left(\mathrm{NMe}_{2}\right)_{3}\right\}\right]$ was further demonstrated in the challenging hydration of cyanohydrins ( $\alpha$-hydroxynitriles), substrates usually difficult to hydrate because they degrade to produce cyanide which poisons the catalysts. As shown in Scheme 7, using $5 \mathrm{~mol} \%$ of the $p$ cymene complex $\left[\mathrm{RuCl}_{2}\left(\eta^{6}-p\right.\right.$-cymene $\left.)\left\{\mathrm{P}\left(\mathrm{NMe}_{2}\right)_{3}\right\}\right]$ (11), and performing the catalytic reactions at room temperature within the $\mathrm{pH}$ range 3.5-8.5 to minimize the decomposition of the substrates into the corresponding aldehydes and $\mathrm{HCN}$, glycolonitrile and lactonitrile could be completely transformed into the corresponding $\alpha$-hydroxyamides [48,49].

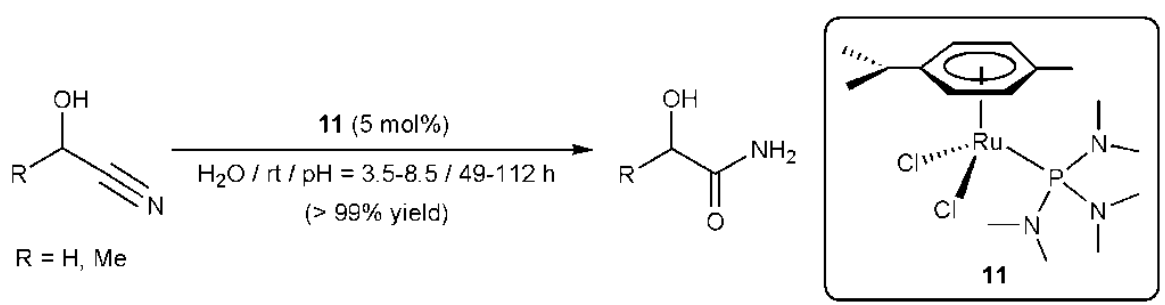

Scheme 7. Cyanohydrins hydration using $\left[\mathrm{RuCl}_{2}\left(\eta^{6}-p\right.\right.$-cymene $\left.)\left\{\mathrm{P}\left(\mathrm{NMe}_{2}\right)_{3}\right\}\right](11)$ as catalyst.

The H-bond accepting properties of tris(dimethylamino)phosphine were again evoked to explain the excellent catalytic activities observed, a cooperative effect that was supported by DFT calculations (Figure 4) [49]. Secondary coordination sphere activation of water, via hydrogen bonding with the OH group of the ligand, also explains the outstanding performances of the related phosphiniteruthenium(II) complex $\left[\mathrm{RuCl}_{2}\left(\eta^{6}-p\right.\right.$-cymene $\left.)\left\{\mathrm{PMe}_{2}(\mathrm{OH})\right\}\right](\mathbf{1 2})$, which was also able to hydrate cyanohydrins [50,51]. Although other catalytic systems for the selective hydration of organonitriles in water have been described [52-57], none of them presented an activity and scope comparable to those of the bifunctional catalysts 4-12. 


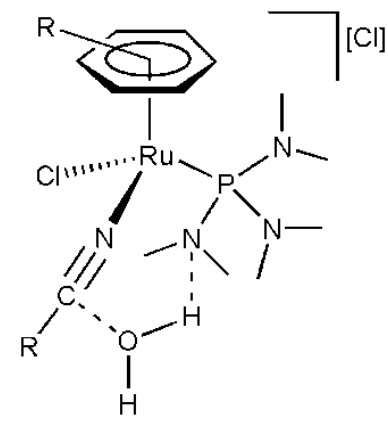

Figure 4. The cooperative effect of the tris(dimethylamino)phosphine ligand.

Additional examples of nitrile hydration reactions catalyzed by homogeneous ruthenium catalysts in organic media are (Scheme 8): (i) The hydration of benzoxazolylacetonitrile by the arene-ruthenium(II) dimer $\left[\left\{\mathrm{RuCl}(\mu-\mathrm{Cl})\left(\eta^{6}-p \text {-cymene }\right)\right\}_{2}\right]$, which led to benzoxazolylacetamide in high yield [58], and (ii) the asymmetric hydration of $\alpha$-benzyl- $\alpha$-methylmalononitrile by the chiral catalysts 13 [59]. Modest yields and low enantiomeric excesses were obtained in this latter reaction. However, we must note that this is the first example of a non-enzymatic asymmetric nitrile hydration process reported to date in the literature.

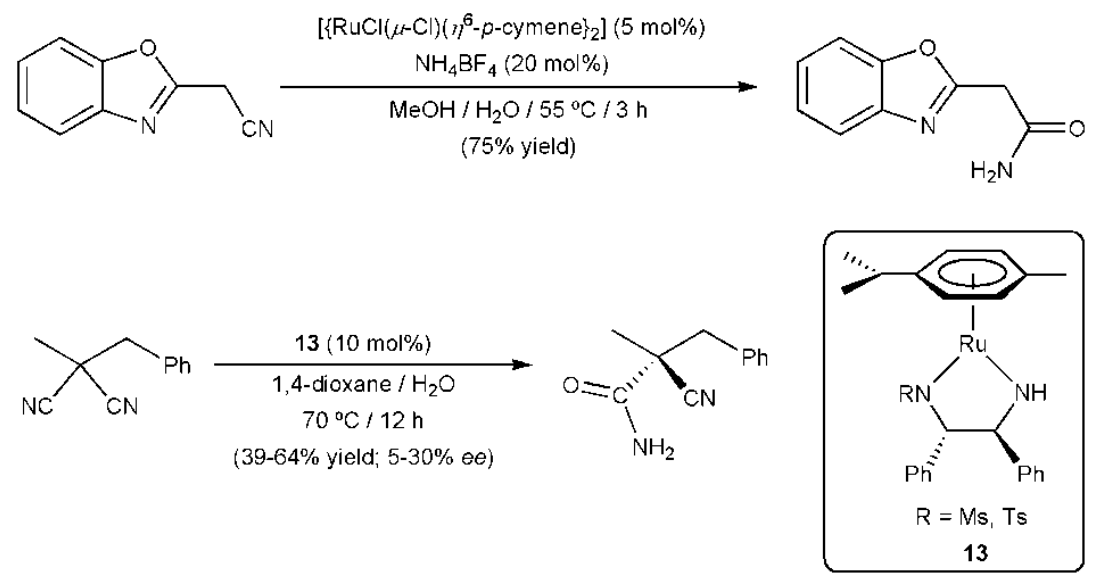

Scheme 8. Some nitrile hydrations catalyzed by ruthenium(II) complexes.

On the other hand, different heterogeneous ruthenium-based systems able to promote the selective hydration of nitriles to amides have also been developed. A 
benchmark in the field was described by Mizuno and co-workers in 2004 employing ruthenium hydroxide supported on alumina $\left(\mathrm{Ru}(\mathrm{OH})_{\mathrm{x}} / \mathrm{Al}_{2} \mathrm{O}_{3}\right)$ as catalyst [60]. This system was able to operate directly in water, showed a great substrate scope, and led to TOF and TON values of up to $13 \mathrm{~h}^{-1}$ and 234 , respectively, at $140{ }^{\circ} \mathrm{C}$. Worthy of note, the use of organic solvents was not needed during workup since the solid catalyst could be separated from the reaction mixture by hot filtration at $90{ }^{\circ} \mathrm{C}$, and the amides crystallized in pure form from the filtrate upon cooling at 0 ${ }^{\circ} \mathrm{C}$. In addition, the heterogeneous $\mathrm{Ru}(\mathrm{OH})_{\mathrm{x}} / \mathrm{Al}_{2} \mathrm{O}_{3}$ system could be reused two times without significant loss of catalytic activity. A mechanism involving the coordination of the nitrile to ruthenium on the surface of $\mathrm{Ru}(\mathrm{OH})_{\mathrm{x}} / \mathrm{Al}_{2} \mathrm{O}_{3}$, followed by attack of a ruthenium hydroxide species on the coordinated nitrile, was proposed (Scheme 9).

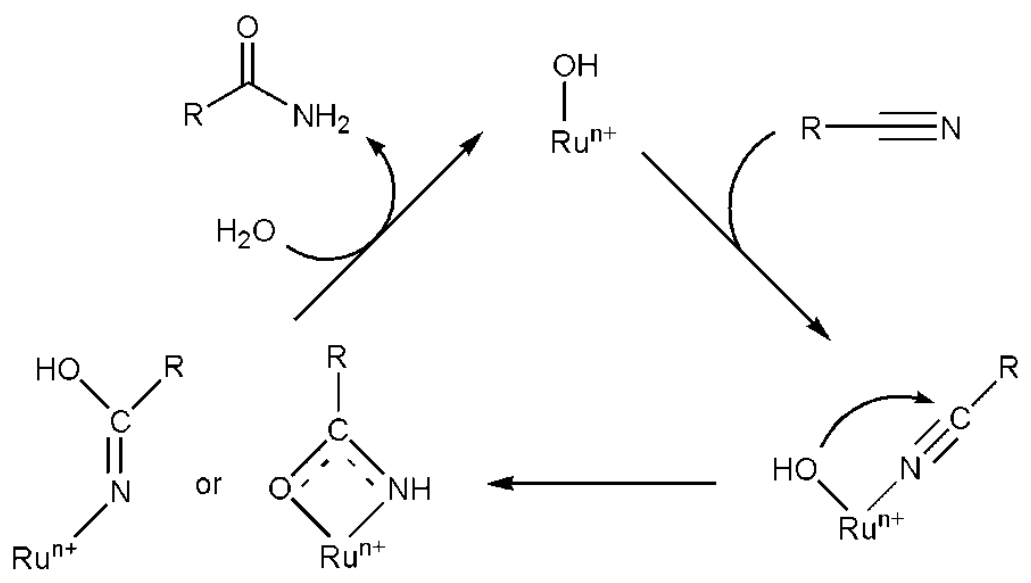

Scheme 9. Proposed mechanism for the catalytic hydration of nitriles promoted by $\mathrm{Ru}(\mathrm{OH})_{\mathbf{x}} / \mathrm{Al}_{2} \mathrm{O}_{3}$.

Related organic solvents-free protocols were described employing as catalysts ruthenium hydroxide supported on dopamine-functionalized $\mathrm{Fe}_{3} \mathrm{O}_{4}$ nanoparticles 14 $[61,62], \mathrm{Ru}(\mathrm{OH})_{\mathrm{x}}$ nanoparticles supported on silica-coated $\mathrm{Fe}_{3} \mathrm{O}_{4}$ nanoparticles $\mathbf{1 5}$ [63], and the arene-ruthenium(II) complex supported on silica-coated $\mathrm{Fe}_{3} \mathrm{O}_{4}$ nanoparticles 16 [64] (Figure 5). All these nanocatalysts showed excellent activities (TOFs up to $170 \mathrm{~h}^{-1}$ ) and selectivities for a broad range of activated and inactivated benzonitriles, as well as heteroaromatic, aliphatic and $\alpha, \beta$-unsaturated nitriles, leading to the corresponding primary amides in high yields (70-95\%) after $0.5-7 \mathrm{~h}$ of MW irradiation at $100-150{ }^{\circ} \mathrm{C}$ in pure water. The paramagnetic nature of the nano-ferrites-based supports enabled an easy catalyst/product separation just by applying an external magnet. The recovered catalysts could be reused three (14- 
15) or six (16) times, and the amides isolated by simple crystallization from the aqueous solutions.

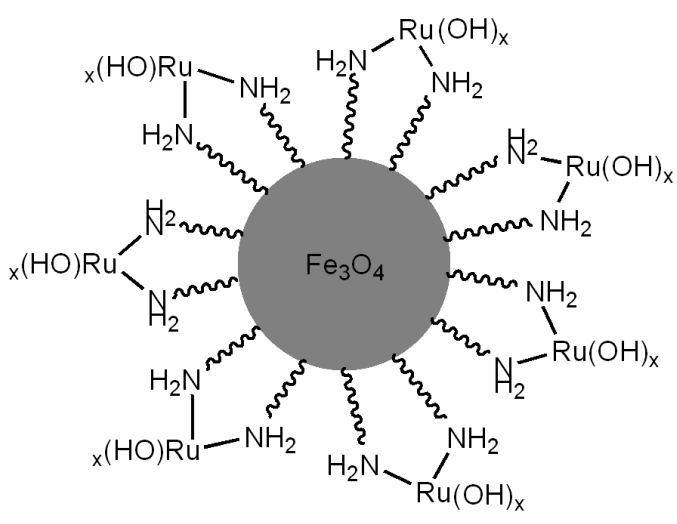

14<smiles>NCCc1ccc2c(c1)OBSP2</smiles>

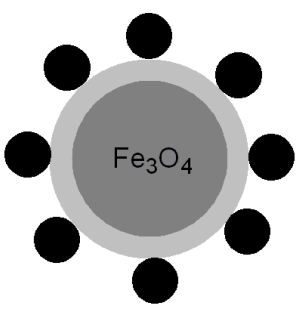

15

$=\mathrm{Ru}(\mathrm{OH})_{x}$ nanoparticles

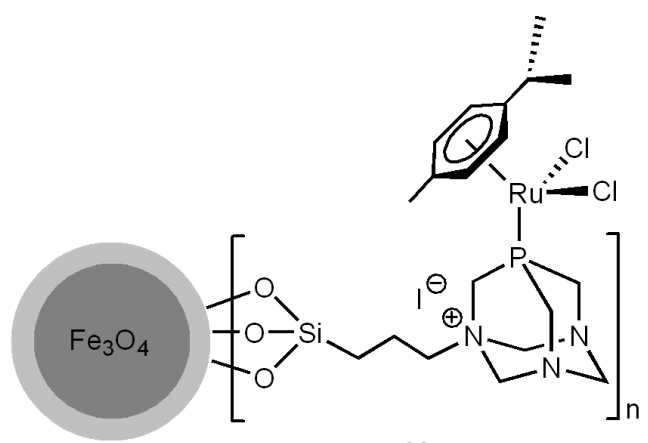

16

= silica layer

Figure 5. Structure of the heterogeneous ruthenium catalysts 14-16.

Ruthenium-substituted hydroxyapatite $\left((\mathrm{RuCl})_{2} \mathrm{Ca}_{8}\left(\mathrm{PO}_{4}\right)_{6}(\mathrm{OH})_{2}\right)$ [65], the modified nafion resin 17 (Figure 6) [66] and a series of ruthenium nanoparticles supported on carbon [67], alumina [68], polyvinylpyrrolidone (PVP) [69] and the ion exchange polystyrene resin Amberlite IRA 900 chloride [70] are other heterogeneous ruthenium-based nitrile hydration catalysts described in the literature. All of them were active in pure water and recoverable by filtration. However, their activities and substrate scope were, in general, comparatively lower with regard to those of the magnetic nanocatalysts 14-16. 


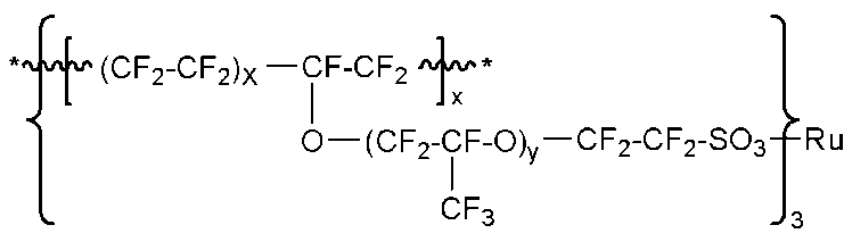

17

Figure 6. Structure of the nafion-Ru resin 17.

\section{Ruthenium-Catalyzed Hydrolytic Amidation of Nitriles with} Amines

Despite the great advances reached in the catalytic nitrile hydration, reactions to form $N$-substituted amides from nitriles have few precedents. In this context, although little studied, the catalytic amidation of nitriles with amines in the presence of water has emerged in recent years as a useful tool for the straightforward generation of secondary and tertiary amides (Scheme 10) [71-77].<smiles>[R][R]N[N+]#C[R]</smiles>

Scheme 10. The hydrolytic amidation of nitriles with amines.<smiles>NCCCCNCCCNC(=O)/C=C/c1ccccc1</smiles>

Scheme 11. Ruthenium-catalyzed synthesis of maytenine.

This amidation reaction was reported for the first time by Murahashi and coworkers in 1986 using the unique ruthenium catalyst described so far for this catalytic transformation [78]. Thus, they were able to synthesize a large variety of $N$ - 
substituted amides from different nitrile/amine combinations by performing the catalytic reactions in DME at $160{ }^{\circ} \mathrm{C}$ with $3 \mathrm{~mol} \%$ of the ruthenium(II)-dihydride complex $\left[\mathrm{RuH}_{2}\left(\mathrm{PPh}_{3}\right)_{4}\right]$ and 2 equivalents of water $[25,26,78]$. The high yield preparation of the maytenine alkaloid 20, by coupling of cinnamonitrile $\mathbf{1 8}$ with the triamine 19, is an illustrative example of the synthetic utility of this amidebond-forming process (Scheme 11).

As shown in Scheme 12, the intramolecular version of the reaction provided an efficient method for the catalytic synthesis of lactams [78].
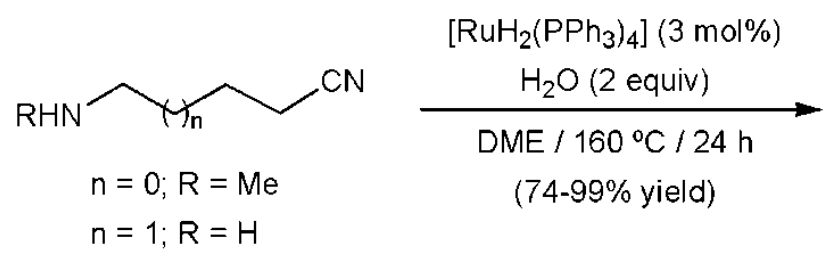<smiles>[R]N1CCCCC1=O</smiles>

Scheme 12. Ruthenium-catalyzed synthesis of lactams by intramolecular hydrolytic amidation.

Murahashi and co-workers also demonstrated the utility of this catalytic transformation for the preparation of industrially relevant polyamides, as exemplified in the reaction of adiponitrile with 1,6-hexanediamine to give the nylon-6,6 polymer (Scheme 13) [78].

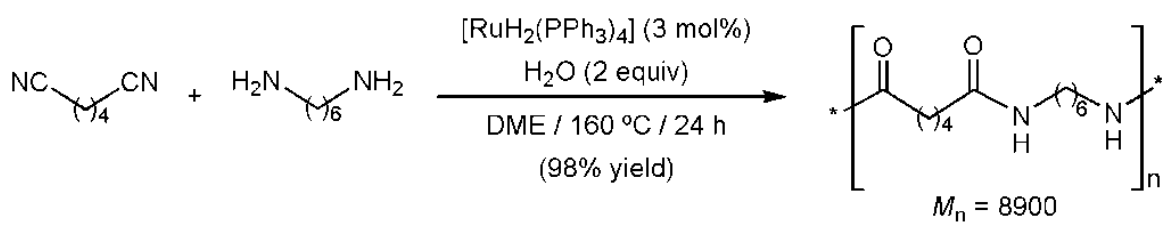

Scheme 13. Ruthenium-catalyzed synthesis of the polymer nylon-6,6.

Mechanistic studies by Duchateau and co-workers, employing the $\left[\mathrm{RuH}_{2}\left(\mathrm{PPh}_{3}\right)_{4}\right]-$ catalyzed hydrolytic amidation of pentanenitrile with $n$-hexylamine as model reaction, pointed out that the process proceeds through the initial hydration of the nitrile to form an intermediate primary amide, which subsequently reacts with the amine to give the final $N$-substituted amide product (parth (a) in Scheme 14) [79]. This reaction pathway contrasts with that commonly proposed for other homogeneous metal catalysts (Pt-, $\mathrm{Cu}$ - $\mathrm{Zn}$ - or Fe-based systems) where an amidine intermediate, which evolves into the final amide product by hydrolysis, is initially formed (parth (b) in Scheme 14) [71,73,75-77]. 


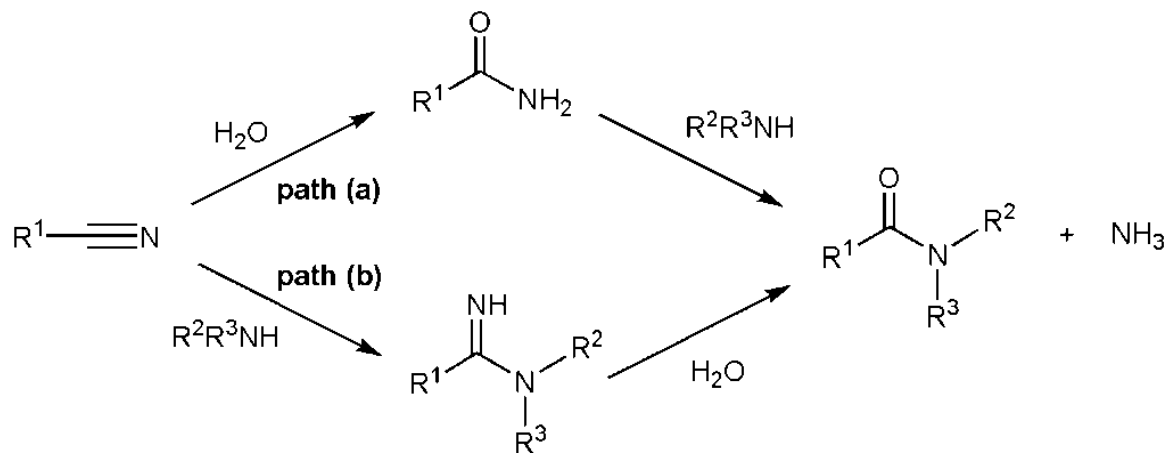

Scheme 14. Possible reaction pathways for the catalytic amidations of nitriles with amines.

\section{Ruthenium-Catalyzed Rearrangement of Aldoximes}

Although the first report on metal-catalyzed rearrangement of aldoximes dates back to the early 1960's [80], only in recent years this transformation appeared to be an attractive method for synthesizing primary amides [81]. The main advantages of this reaction stem from its total atom economy and the availability of the starting materials, which are easily accessible by condensation of an aldehyde with hydroxylamine. From a mechanistic point of view, two main reaction pathways have been proposed. The first one consists of the initial dehydration of the aldoxime to form a nitrile, which is further rehydrated by the water molecule released in the previous step (Scheme 15, path (a)). The second mechanism also starts with the dehydration of the aldoxime into a nitrile, which now reacts with a second molecule of aldoxime, acting as a water surrogate, to deliver the free amide and regenerate the active metal-nitrile species (Scheme 15, path (b)). Remarkably, although pathway (a) has been the generally accepted mechanism, a recent study of Williams and co-workers using ${ }^{18} \mathrm{O}$-labeled substrates revealed that most of the catalytic systems reported to date operate indeed through the pathway (b) [82].

The first examples of the rearrangement of aldoximes into primary amides involving a ruthenium catalyst, namely $\left[\mathrm{Ru}(\mathrm{cod})(\mathrm{py})_{4}\right]\left[\mathrm{BPh}_{4}\right]_{2}$, were reported by Kiji and co-workers in 1982 [83]. However, efficient and general ruthenium-based protocols did not appear till 2007, when Williams and co-workers described the activity of the ruthenium-dihydride complex $\left[\mathrm{RuH}_{2}(\mathrm{CO})\left(\mathrm{PPh}_{3}\right)_{3}\right]$ associated with different bidentate ligands [84]. The best performances were obtained with 1,2bis(diphenylphosphino)ethane (dppe) (Scheme 16). Moreover, the addition of 4 equivalents of $p$-toluenesulfonic acid per ruthenium to the reaction medium was required to achieve good rates and selectivities. Under these optimal conditions, 
both aromatic or aliphatic aldoximes, as well as $\alpha, \beta$-unsaturated ones, could be converted into the corresponding primary amides in excellent yields.

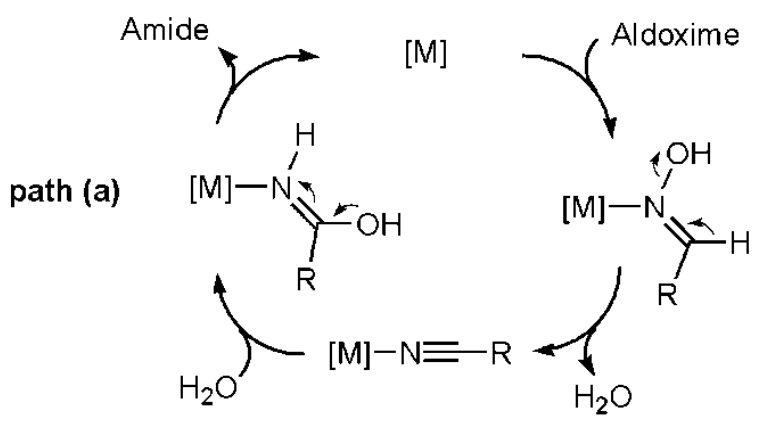<smiles>[R]C=C(CC(C)CO)[N+]([O-])O</smiles>

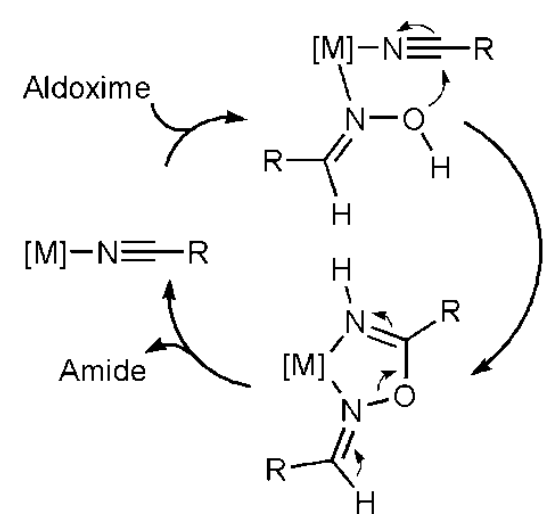

Scheme 15. Proposed mechanisms for the metal-catalyzed rearrangement of aldoximes.

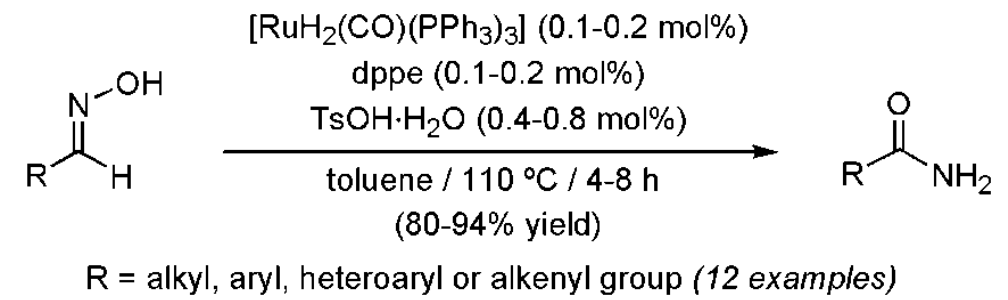

Scheme 16. Ruthenium-catalyzed rearrangement of aldoximes into primary amides.

A more convenient additive-free protocol was developed a couple of years later using $1 \mathrm{~mol} \%$ of the octahedral ruthenium complex $\left[\mathrm{RuCl}_{2}\left(\mathrm{PPh}_{3}\right)(\right.$ terpy) $]$ [85]. 
Aldoximes with both syn and anti conformation could be employed, with no difference in the rate of the isomerization process. This catalytic system proved to be also useful for the rearrangement of aldoximes generated in situ from the corresponding aldehydes. Thus, as shown in Scheme 17, the heating of a 1:1:1 mixture of the aldehyde, hydroxylammonium chloride and $\mathrm{NaHCO}_{3}$, in the presence of $\left[\mathrm{RuCl}_{2}\left(\mathrm{PPh}_{3}\right)\right.$ (terpy)] (1 mol\%), selectively led to the desired primary amides in good yields.

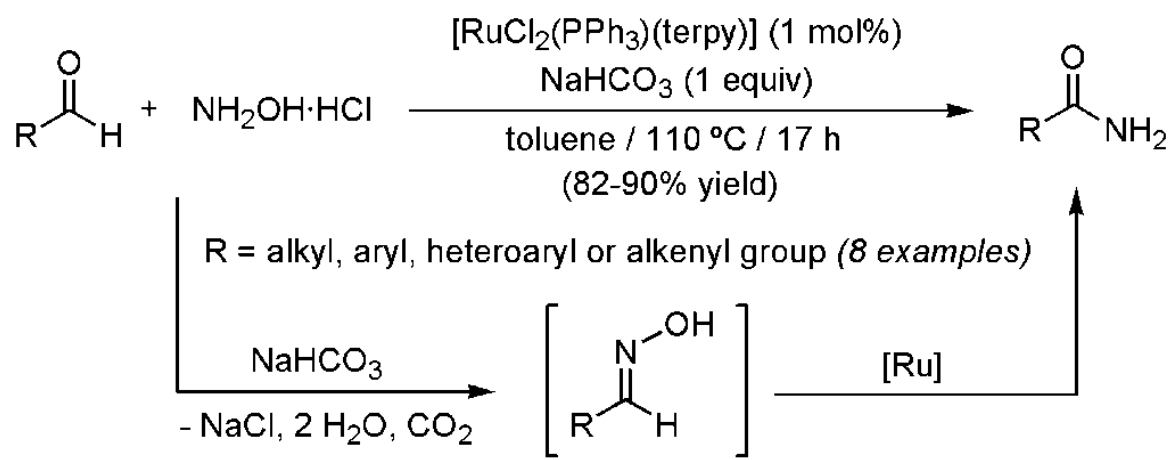

Scheme 17. Ru-catalyzed rearrangement of aldoximes generated in situ from aldehydes.

Since then, different octahedral ruthenium(II) complexes ( $1 \mathrm{~mol} \%$ ) have been employed to generate primary amides through the direct rearrangement of isolated aldoximes (21 in Figure 7), or through the one-pot coupling of aldehydes with hydroxylammonium salts (22-24 in Figure 7) [86-89]. Both processes were also catalyzed by $\left[\mathrm{RuCl}_{2}(\mathrm{DMSO})_{4}\right]$, albeit a higher metal loading $(5 \mathrm{~mol} \%)$ was in this case needed [90].

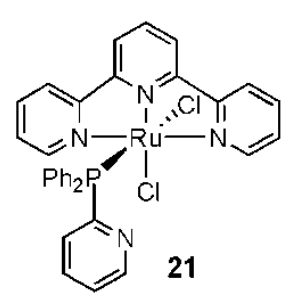

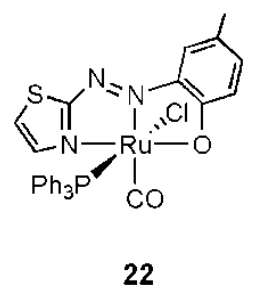

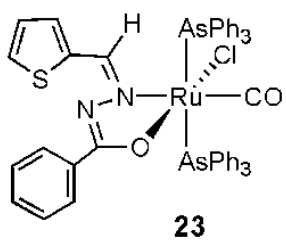

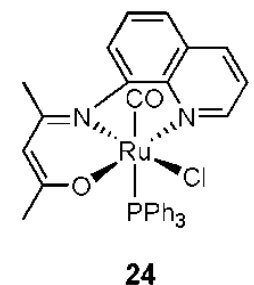

Figure 7. Structure of the ruthenium(II) complexes 21-24.

Interestingly, using $5 \mathrm{~mol} \%$ of the arene-ruthenium(II) complex $\left[\mathrm{RuCl}_{2}\left(\eta^{6}-\right.\right.$ $\left.\left.\mathrm{C}_{6} \mathrm{Me}_{6}\right)\left\{\mathrm{P}\left(\mathrm{NMe}_{2}\right)_{3}\right\}\right]$ (10 in Scheme 6), the rearrangement of aldoximes could be successfully performed in aqueous medium at $100{ }^{\circ} \mathrm{C}$ [91]. Kinetic studies and ex- 
periments in ${ }^{18} \mathrm{O}$-labeled water indicated that, for this particular catalyst, the reaction proceeds simultaneously through the two mechanisms depicted in Scheme 15, albeit pathway (b) showed to be predominant. This aqueous methodology was applicable to a wide range of aromatic, heteroaromatic, aliphatic and $\alpha, \beta$-unsaturated aldoximes (39 examples). The synthetic utility of complex $\mathbf{1 0}$ was fully demonstrated in the preparation of the chiral amides $(S)-(-)$-citronellamide $(\mathbf{2 5}),(S)$-(-)perillamide (26) and (1R)-(-)-myrtenamide (27), compounds of relevance in the fragrance industry (Figure 8$)$.

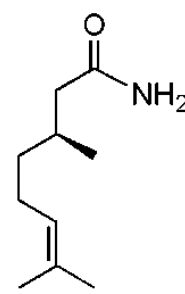

25<smiles>C=C(C)[C@H]1CC=C(C(N)=O)CC1</smiles>

26

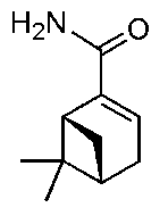

27

Figure 8. Structure of the optically active amides 25-27.

Complex $\left[\mathrm{RuCl}_{2}\left(\eta^{6}-\mathrm{C}_{6} \mathrm{Me}_{6}\right)\left\{\mathrm{P}\left(\mathrm{NMe}_{2}\right)_{3}\right\}\right]$ (10) also resulted operative in the onepot synthesis of amides from aldehydes in water [92]. Worthy of note, besides the classical source of the $\mathrm{NH}_{2}$ group, i.e. the $\mathrm{NH}_{2} \mathrm{OH} \cdot \mathrm{HCl}$ salt associated with $\mathrm{NaHCO}_{3}$, commercially available hydroxylamine solution $\left(50 \mathrm{wt} \%\right.$ in $\left.\mathrm{H}_{2} \mathrm{O}\right)$ could also be employed, improving notably the atom economy of the overall process since only water was generated as byproduct. More recently, the highly watersoluble complex 9 (Figure 3), which contains a thiazolyl-phosphine hydrochloride salt as ligand, was also found active in the synthesis of primary amides from aldoximes and aldehydes using water as solvent [45].

On the other hand, the preparation of secondary amides from aldoximes has been recently achieved through the one-pot sequential rearrangement $/ N$-alkylation process depicted in Scheme 18 [93]. The reactions were carried out heating a toluene solution of the aldoxime with a mixture of dimers $\left[\left\{\mathrm{RuCl}(\mu-\mathrm{Cl})\left(\eta^{6}-p \text {-cymene }\right)\right\}_{2}\right]$ and $\left[\left\{\operatorname{IrCl}(\mu-\mathrm{Cl})\left(\eta^{5}-\mathrm{C}_{5} \mathrm{Me}_{5}\right)\right\}_{2}\right]$, followed by the addition of an alcohol and $\mathrm{Cs}_{2} \mathrm{CO}_{3}$ to the medium. Under these conditions selective formation of $\mathrm{N}$ monoalkylated amides occurred, primary or $N, N$-dialkylated ones being not detected at the end of the reactions. Although the two steps involved in the process could be promoted by both ruthenium and iridium species alone, the initial rearrangement of the aldoxime was particularly favored in the presence of $\mathrm{Ru}$, while the $\mathrm{N}$-alkylation of the resulting primary amide was more effective with Ir. Therefore, the combination of the two metals resulted more advantageous than their use separately. The methodology proved to be general and it was successfully applied to a variety of aromatic, heteroaromatic and aliphatic aldoximes. Benzyl or alkyl 
primary alcohols were satisfactorily involved in the $\mathrm{N}$-alkylation step, but the secondary and tertiary ones, much more hindered, were not tolerated.

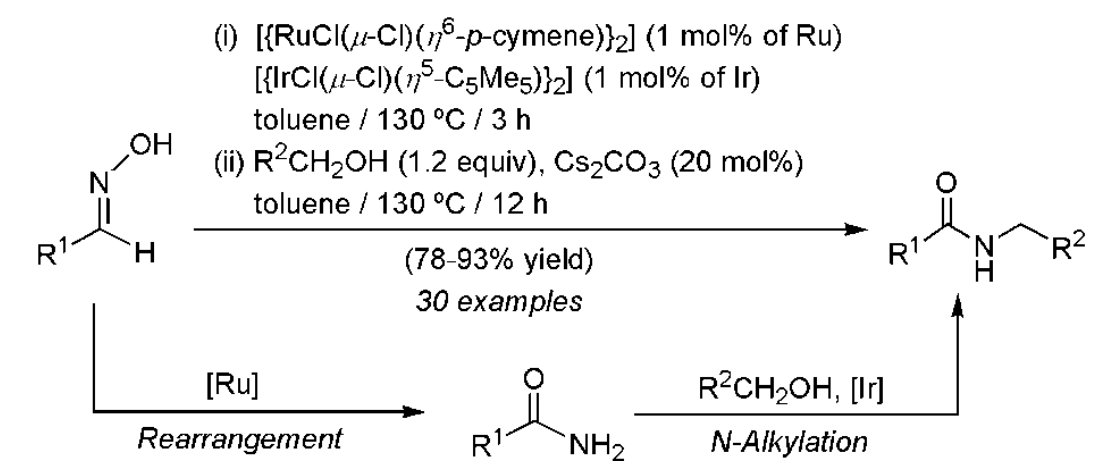

Scheme 18. Synthesis of secondary amides from aldoximes through sequential rearrangement $/ N$-alkylation reactions.

\section{Ruthenium-Catalyzed Dehydrogenative Amidations}

\subsection{Starting from alcohols}

The catalytic oxidative dehydrogenation of primary alcohols in the presence of amines has emerged in recent years as an attractive alternative for the synthesis of amides $[94,95]$. The reaction is assumed to take place through the initial dehydrogenation of the alcohol into the corresponding aldehyde, followed by nucleophilic attack of the amine and subsequent dehydrogenation of the resulting hemiaminal (Scheme 19). In these dehydrogenative processes, esters [95,96], imines [97] and amines $[95,96,98]$ can also be generated through competing reaction pathways (Scheme 19). The selectivity towards amides strongly depends on the nature of substrates and catalysts, as well as on the experimental conditions employed, but, despite the great advances reached in this area during the last years, the factors that govern the outcome of the reaction are still little understood. Actually, the number of catalytic systems active in dehydrogenative amidation processes, most based on ruthenium complexes, is by far smaller than those able to promote the formation of amines or esters [95,96,98].

Pioneering work in the field was reported by Murahashi and co-workers in 1991 [99]. They discovered that 1,4- and 1,5-amino-alcohols can be selectively converted into lactams, through an intramolecular coupling, in the presence of catalytic 
amounts of the ruthenium-dihydride derivative $\left[\mathrm{RuH}_{2}\left(\mathrm{PPh}_{3}\right)_{4}\right]$ (Scheme 20). With this system, the use of at least two equivalents of a hydrogen acceptor, such as benzalacetone, was needed to achieve high conversions and selectivities in the desired cyclic amides. Moreover, the substrates bearing a primary amino group $(\mathrm{R}=$ $\mathrm{H}$, in Scheme 20) required a two-fold excess of water in order to prevent the competing formation of a cyclic amine, the latter resulting from the dehydration of the hemiaminal intermediate and subsequent hydrogenation of the resulting imine.

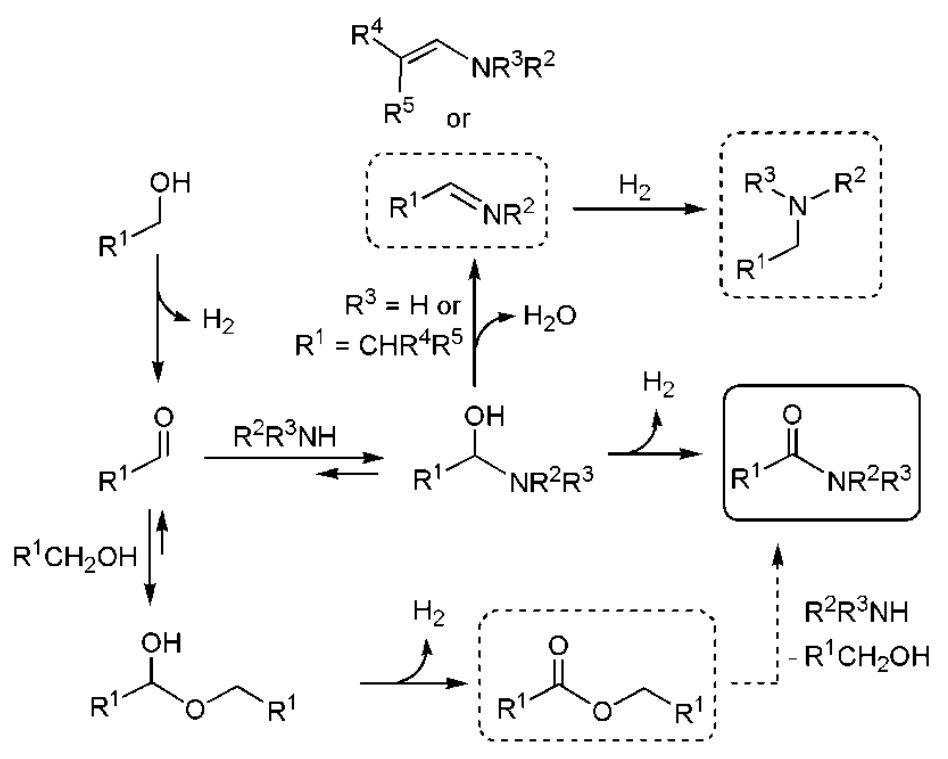

Scheme 19. Dehydrogenative amidation of primary alcohols and competing processes.

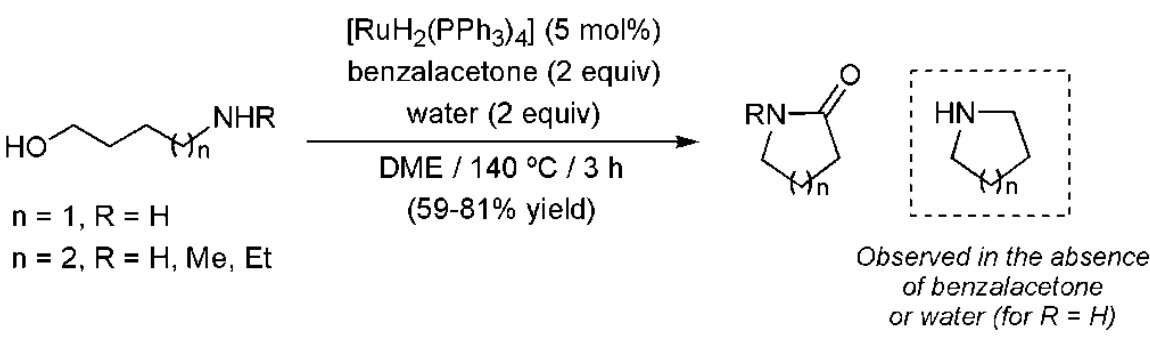

Scheme 20. Synthesis of lactams promoted by $\left[\mathrm{RuH}_{2}\left(\mathrm{PPh}_{3}\right)_{4}\right]$.

This amidation process, poorly exploited till 2007 [100], regained popularity after Milstein's report on a highly efficient and atom-economical procedure that did not 
require of a sacrificial hydrogen acceptor, the oxidations of the alcohol and the hemiaminal proceeding with formation of hydrogen gas as the only by-product [101]. The catalytic system, based on the PNN-pincer ruthenium derivative 28, was successfully applied to the highly selective synthesis of a variety of secondary amides from 1:1 mixtures of primary alcohols and amines (Scheme 21). However, when amines with only a moderate nucleophilic character were employed as substrates, small amounts of esters were also formed as by-products.

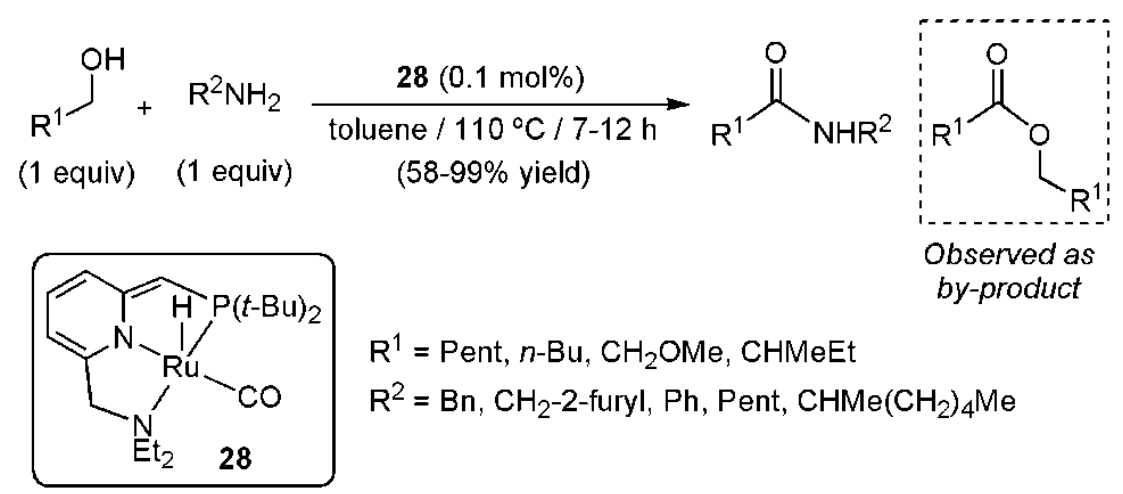

Scheme 21. Acceptorless-protocol to generate secondary amides from alcohols and amines.

The efficient removal of $\mathrm{H}_{2}$ during the course of the reaction appeared to be crucial. In this sense, high yields in the amides were obtained when the reactions were performed in refluxing toluene under a flow of argon, while lower conversions and selectivities were reached in a closed system. Alternatively, the catalytic reactions could be performed in the presence of the related air-stable hydrochloride complex $[\mathrm{RuClH}(\mathrm{CO})(\mathrm{PNN})]$ (29 in Figure 9) associated with one equivalent (per $\mathrm{Ru}$ ) of base [102]. Under these basic conditions, 29 is quantitatively converted into 28 through the deprotonation of the tridentate ligand backbone [103]. The high efficiency of $\mathbf{2 8}$ and $\mathbf{2 9}$ is ascribed to the cooperation of the PNN-pincer ligand in the different $\mathrm{H}$-atom transfers involved in the reaction, through reversible aromatization/dearomatization processes of the pyridine-based core [102-107]. Surprisingly, under similar experimental conditions, the analogous PNP-pincer derivatives $\mathbf{3 0}$ and $\mathbf{3 1}$ (Figure 9), susceptible to undergo related aromatization/dearomatization processes of the ligand, produced imines selectively instead of amides [97,103]. The authors attributed this different chemical behavior to the lack of a hemilabile group in the catalysts' structure (i.e. absence of the $\mathrm{CH}_{2} \mathrm{NEt}_{2}$ arm). However, we must note that later DFT calculations suggested that electronic properties rather govern the outcome of the reaction [105-107].

The catalytic protocol based on complex $\mathbf{2 8}$ proved to be also suitable for the bisacylation of diamines with simple alcohols [101]. In addition, polyamines with 
both primary and secondary groups reacted with complete chemoselectivity at the $\mathrm{NH}_{2}$ positions keeping untouched the $\mathrm{NH}$ functions, without the need of a protection/deprotection strategy. The methodology was extended, separately by Guan [108] and Milstein $[109,110]$, to the synthesis of polyamides starting from diols and diamines (representative examples are given in Scheme 22). The replacement of toluene by a more solubilizing solvent (i.e. anisole, anisole:DMSO or 1,4dioxane) proved to be crucial to obtain high molecular weight polymers (up to $28.4 \mathrm{kDa})$.

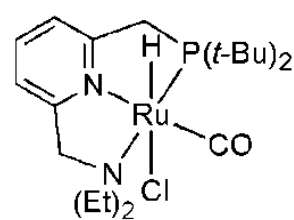

29

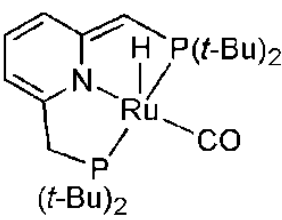

30

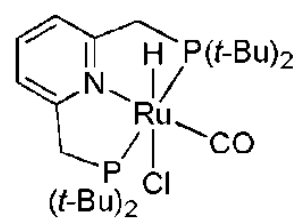

31

Figure 9. Structure of the PNN- and PNP-pincer complexes 29-31.
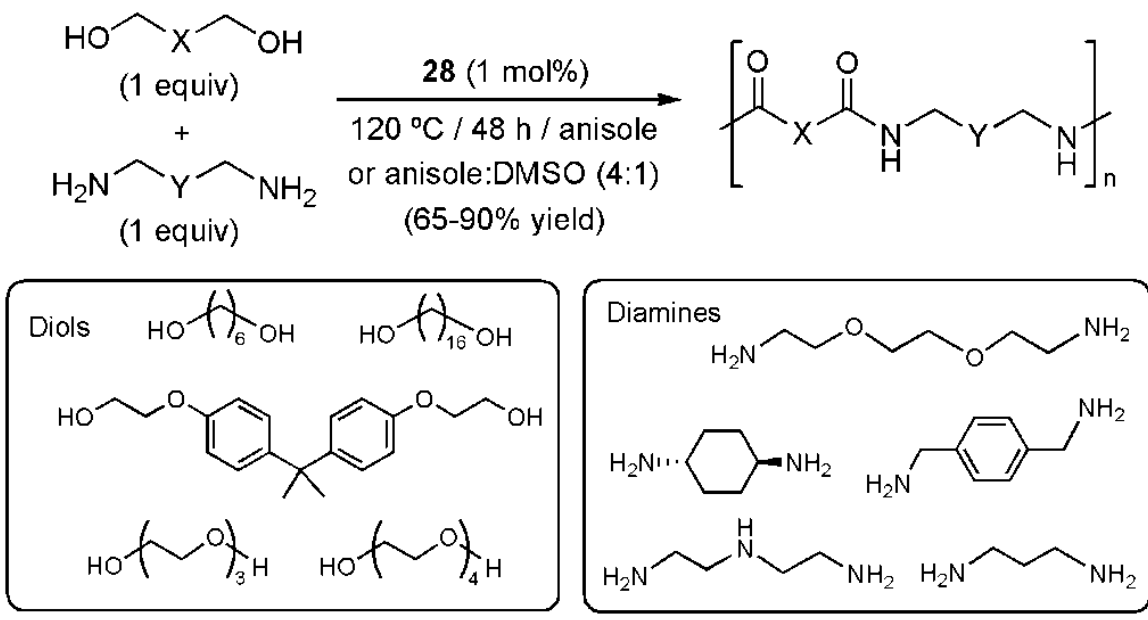

Scheme 22. Synthesis of polyamides through dehydrogenative processes.

The formation of polyamides also occurred in the self-coupling of sterically nonhindered 1,2-amino-alcohols [111]. However, when substrates with large substituents in $\alpha$-position with respect to the amino group were employed, diketopiperazines 32 were instead selectively obtained (Scheme 23). Interestingly, the transformation of chiral amino-alcohols took place without epimerization, affording the cyclic dipeptides 32 in optically pure form. This methodology was also operative 
with the cyclic secondary amino-alcohol $(S)$-prolinol, thus allowing the preparation of the tricyclic product 33. Once again, a striking difference in reactivity was observed when using complex $\mathbf{3 0}$ as catalyst, pyrazines $\mathbf{3 4}$ being in this case the major reaction products [111].

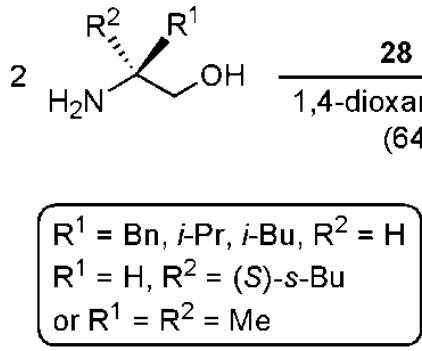

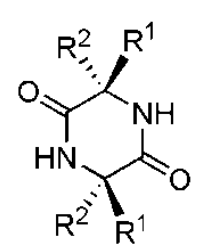

32

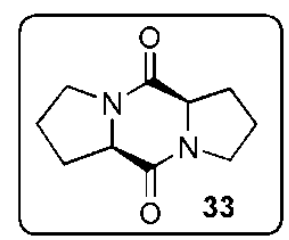<smiles>[R]c1cc(I)ncc1CI</smiles>

Formed with $\mathbf{3 0}$

(when $R^{1}$ or $R^{2}=H$ )

Scheme 23. Synthesis of 3,6-disubstituted-piperazine-2,5-diones promoted by complex 28 .

In addition to the PNN-pincer derivative 28, other transition metal catalysts, associated or not with a hydrogen acceptor, have been developed for the dehydrogenative amidation of alcohols with amines. Ruthenium complexes, and especially NHC-compounds, have been the most widely studied [94], albeit highly efficient processes promoted by rhodium or silver have also been described $[112,113]$. In regard to ruthenium, both in-situ-generated catalytic systems (Table 1) [114-123] as well as well-defined catalysts 38-44 (Figure 10) [124-131] have been reported. In most of the cases, high metal loadings (usually $5 \mathrm{~mol} \%$ ) and an excess of a strong base $(10-40 \mathrm{~mol} \%$ of $\mathrm{NaH}$ or $\mathrm{KO}-t-\mathrm{Bu})$ were required to achieve satisfactory yields in the amides. In general, the reactions showed to be strongly sensitive to the steric hindrance of the substrates. Thus, branched primary alcohols and amines, such as 2,2-dimethylpropanol, 2-methylbutanol or 2-heptanamine, gave rise to lower conversions than the linear ones [101,115,116,119,124,125,129]. In the same line, cyclic secondary amines (e.g. morpholine, piperidine or $\mathrm{N}$ methylpiperazine) provided the corresponding tertiary amides in good yields, while the non-cyclic ones, more sterically hindered, resulted poorly reactive or even totally inactive $[114,115]$. For these latter substrates, some yield improvements have been recently achieved using less sterically congested catalysts. For example, modest to good yields were obtained with the ruthenium complex 39 (Figure 10) bearing diphenylphosphino- and pyridyl-fragments, whereas the relat- 
ed compounds 28 and $\mathbf{2 9}$, with bigger $(t-\mathrm{Bu})_{2} \mathrm{P}$ and $\mathrm{NEt}_{2}$ groups resulted inoperative under the same reaction conditions [129].

Table 1. Examples of ruthenium-based catalytic systems generated in situ.
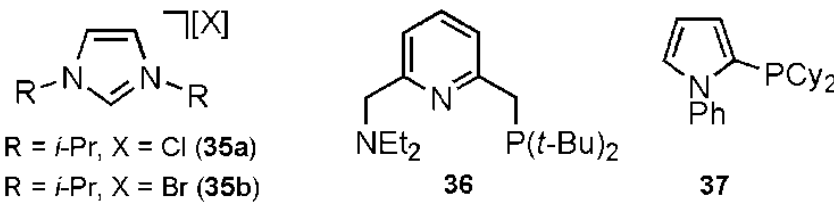

Catalytic system $^{a}$

Reference

$\left[\mathrm{RuCl}_{2}(\mathrm{cod})\right]_{\mathrm{n}}(5 \mathrm{~mol} \% \mathrm{Ru}), \mathbf{3 5 a}(5 \mathrm{~mol} \%), \mathrm{PCyp}_{3} \cdot \mathrm{HBF}_{4}(5$

$\mathrm{mol} \%), \mathrm{KO}-t-\mathrm{Bu}(20 \mathrm{~mol} \%)$

$\left[\left\{\mathrm{RuCl}(\mu-\mathrm{Cl})\left(\eta^{6}-\mathrm{C}_{6} \mathrm{H}_{6}\right)\right\}_{2}\right](5 \mathrm{~mol} \% \mathrm{Ru}), 35 \mathbf{b}(5 \mathrm{~mol} \%), \mathrm{MeCN}$

(5 mol\%), NaH (15 mol\%), $36 \mathrm{~h}$

$\mathrm{RuCl}_{3}(5 \mathrm{~mol} \%), 35 \mathbf{b}(5 \mathrm{~mol} \%)$, pyridine (5 mol\%), NaH (40 $\operatorname{mol} \%)$

$\left[\mathrm{RuCl}_{2}(\mathrm{I} i \mathrm{Pr})\left(\eta^{6}-p\right.\right.$-cymene $\left.)\right](5 \mathrm{~mol} \%), \mathrm{PCy}_{3}(5 \mathrm{~mol} \%), \mathrm{KO}-t-\mathrm{Bu}$

$(10 \mathrm{~mol} \%)$

$\left[\mathrm{RuH}_{2}\left(\mathrm{PPh}_{3}\right)_{4}\right](5 \mathrm{~mol} \%), 35 \mathbf{b}(5 \mathrm{~mol} \%), \mathrm{MeCN}(5 \mathrm{~mol} \%), \mathrm{NaH}$

$(20 \mathrm{~mol} \%)$

$\left[\mathrm{RuCl}_{2}(\mathrm{I} i \mathrm{Pr})\left(\eta^{6}-p\right.\right.$-cymene $\left.)\right](5 \mathrm{~mol} \%), \mathrm{PCy}_{3} \cdot \mathrm{HBF}_{4}(5 \mathrm{~mol} \%)$,

$\mathrm{KO}-t-\mathrm{Bu}(15 \mathrm{~mol} \%)^{b}$

$\left[\mathrm{Ru}\left(\eta^{3}-\mathrm{C}_{3} \mathrm{H}_{4} \mathrm{Me}\right)_{2}(\mathrm{cod})\right](0.2-1 \mathrm{~mol} \%), 36(0.26-1.3 \mathrm{~mol} \%), 20 \mathrm{~h}$

$\left[\mathrm{Ru}_{3}(\mathrm{CO})_{12}\right](1.5 \mathrm{~mol} \% \mathrm{Ru}), 37$ (3 mol\%), in cyclohexane at 140

${ }^{\circ} \mathrm{C}$ for $21 \mathrm{~h}$

$\left[\left\{\operatorname{RuCl}(\mu-\mathrm{Cl})\left(\eta^{6}-p \text {-cymene }\right)\right\}_{2}\right](5 \mathrm{~mol} \% \mathrm{Ru}), \operatorname{dppb}(5 \mathrm{~mol} \%)$,

$\mathrm{Cs}_{2} \mathrm{CO}_{3}$ (10 mol\%), 3-methyl-2-butanone (2.5 equiv) as $\mathrm{H}_{2}-$ acceptor, in $t$ - $\mathrm{BuOH}$ at reflux for $24 \mathrm{~h}$

${ }^{a}$ Reactions performed in toluene at $110{ }^{\circ} \mathrm{C}$ for $24 \mathrm{~h}$, unless otherwise indicated. ${ }^{b} \mathrm{I} i \mathrm{Pr}=1,3-$ diisopropylimidazol-2-ylidene. 

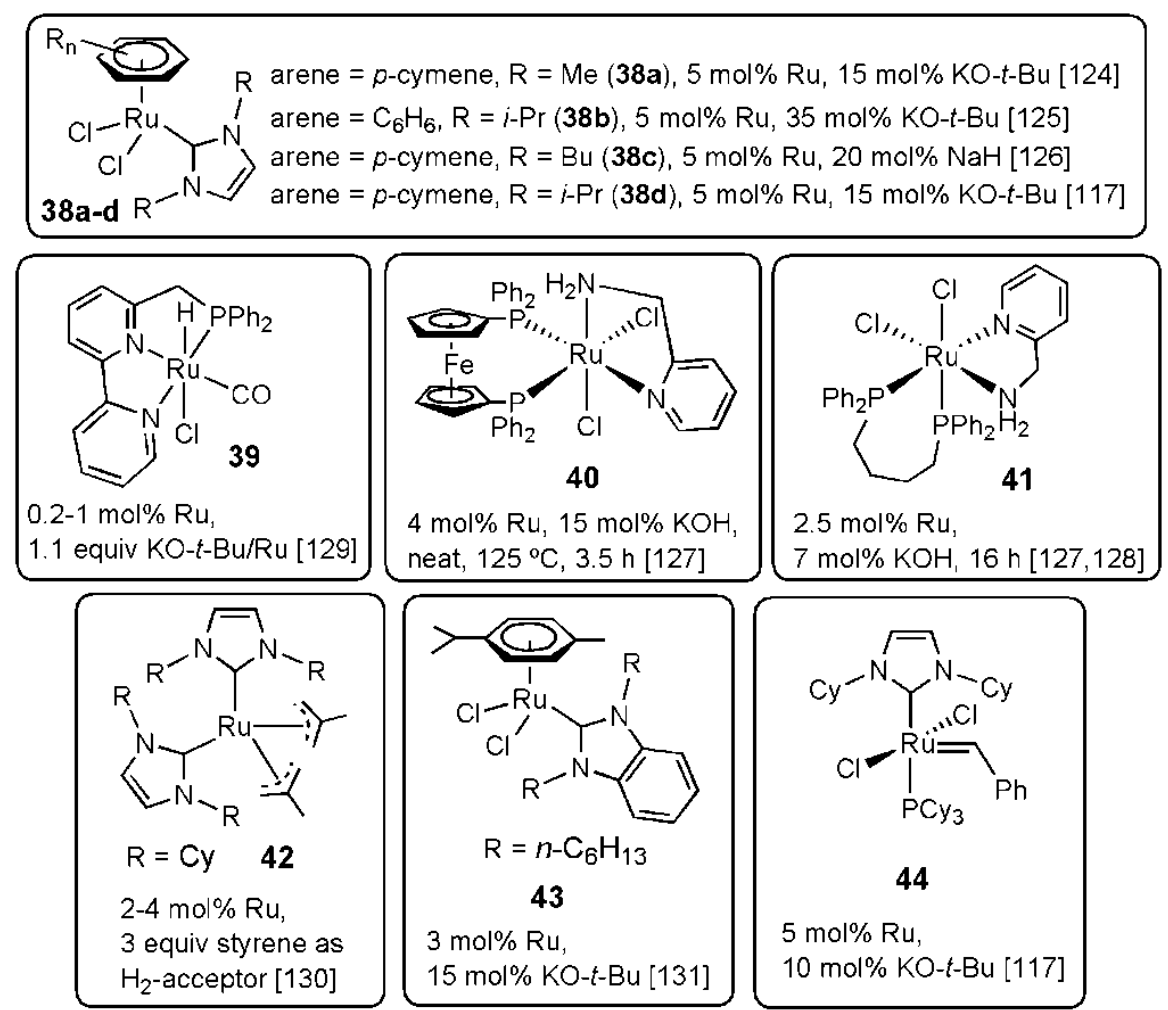

Reactions in toluene at $110^{\circ} \mathrm{C}$ for $24 \mathrm{~h}$, unless otherwise indicated

Figure 10. Structure of well-defined ruthenium catalysts employed in the dehydrogenative amidation of alcohols and experimental conditions.

High base loadings also showed to favor the dehydrogenative coupling of alcohols with hindered secondary amines [125]. Thus, reactions promoted by complex $\left[\mathrm{RuCl}_{2}\left(\eta^{6}-\mathrm{C}_{6} \mathrm{H}_{6}\right)(\mathrm{I} i \mathrm{Pr})\right](\mathbf{3 8 b})$ in combination with $35 \mathrm{~mol} \%$ of $\mathrm{KO}-t$-Bu led to the desired tertiary amides, while the use of only $15 \mathrm{~mol} \%$ of $\mathrm{KO}-t$-Bu resulted in the major formation of esters (Scheme 24). The authors suggested that, in this case, the synthesis of amides takes place through the initial formation of the esters, which further react with the amines (Scheme 19). Accordingly, they evidenced that the direct transformation of esters into amides promoted by $\mathbf{3 8 b}$ was clearly accelerated by adding large amounts of a base to the reaction medium (see Section 5.3).

On the other hand, the dehydrogenative amidation proved to be also sensitive to the electronic properties of the amines. Thus, with electron-poor amines, which display a low nucleophilic character, the formation of the hemiaminal intermediate is disfavored. As a consequence, substrates like anilines usually lead to low or 
moderate conversions, even at elevated temperatures or after long reaction periods, and large amounts of the corresponding esters by-products are formed. In this context, the ruthenium catalysts have conduced, in general, to quite disappointing results $[114,115,117,124]$. In fact, only gold nanoparticles have proven to be useful with this type of amines [132].

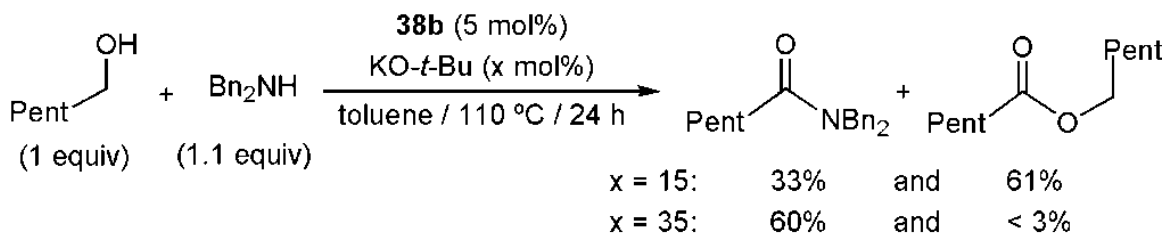

Scheme 24. Effect of the base loading on the synthesis of tertiary amides.

Methanol also represents a challenging substrate for dehydrogenative amidations due to its high energy activation barrier. Till now, only one ruthenium-based catalytic system, developed by Glorius and co-workers, proved to be suitable for the amidation of methanol [130]. Thus, using 2-4 mol\% of the preformed or in-situ generated complex 42 , a variety of primary and secondary amines could be cleanly converted into the corresponding formamides (Scheme 25). Although catalyst 42 could operate without a hydrogen acceptor, highest conversions were reached in the presence of 3 equivalents of styrene.

\section{$42(2-4 \mathrm{~mol} \%)$}

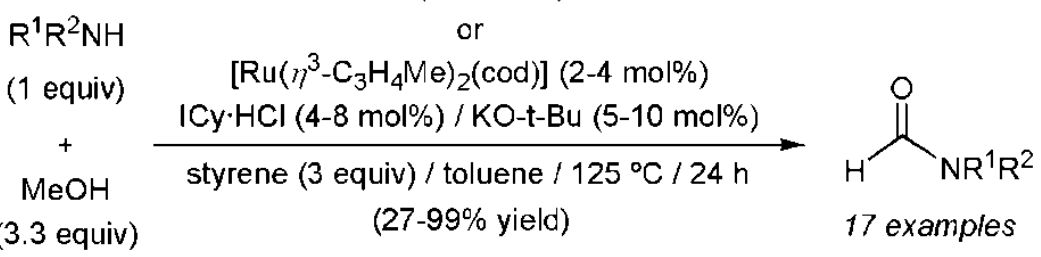

Scheme 25. Ruthenium-catalyzed $N$-formylation of primary and secondary amines.

Gold- and rhodium-catalyzed acylations of ammonia have been reported $[112,132]$, but similar transformations promoted by homogeneous ruthenium catalysts still remain unknown. Such a reaction could only be performed employing a heterogeneous ruthenium-based system under aerobic conditions. However, a completely different mechanism operates in this case (see Section 6) [133].

Interestingly, Hong and co-workers have also demonstrated that the amidation of alcohols can be satisfactorily performed using azides instead of amines as the ni- 
trogen source [134]. The reactions were carried out with $5 \mathrm{~mol} \%$ of the rutheniumdihydride complex $\left[\mathrm{RuH}_{2}\left(\mathrm{PPh}_{3}\right)_{4}\right]$ associated with 1,3-diisopropylimidazolium bromide (35b in Table 1; $5 \mathrm{~mol} \%$ ), acetonitrile ( $5 \mathrm{~mol} \%)$ and $\mathrm{NaH}(20 \mathrm{~mol} \%)$ in refluxing toluene for $48 \mathrm{~h}$. The proposed mechanism involves again the initial dehydrogenation of the primary alcohol into an aldehyde. The hydrogen released in this step reduces the azide, thus generating in situ the corresponding amine (Scheme 26). Worthy of note, this methodology offered an easy entry to ${ }^{15} \mathrm{~N}$ labeled amides starting from ${ }^{15} \mathrm{~N}$-azides, which are readily accessible from alkyl halides and commercially available ${ }^{15} \mathrm{~N}$-labeled $\mathrm{NaN}_{3}$ [134].

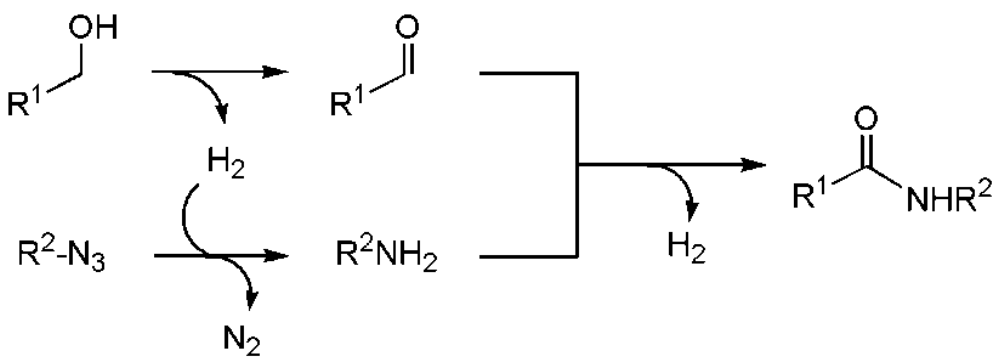

Scheme 26. Proposed mechanism for the dehydrogenative amidation of alcohols with azides.

More recently, the same authors have extended their studies to the synthesis of amides from alcohols and nitriles, via formation of a transient hemiaminal intermediate (Scheme 27) [135]. Among the different catalysts tested, the best performances were reached with the dihydride-ruthenium derivative $\left[\mathrm{RuH}_{2}(\mathrm{CO})\left(\mathrm{PPh}_{3}\right)_{3}\right]$. This synthetic methodology also offered an easy access to ${ }^{13} \mathrm{C}$ - and ${ }^{15} \mathrm{~N}$-labeled amides from isotopically enriched nitriles.

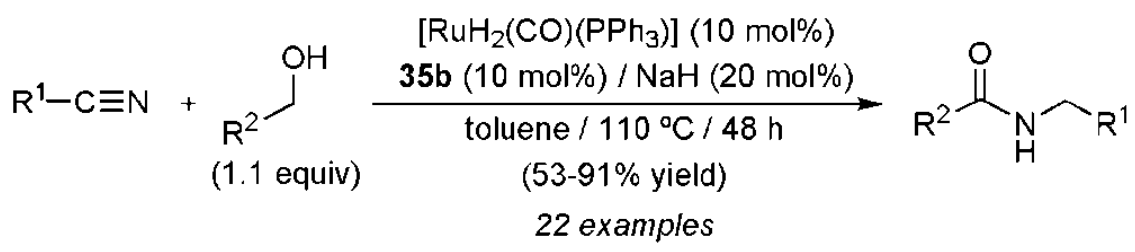

Scheme 27. Ruthenium-catalyzed synthesis of amides from alcohols and nitriles. 


\subsection{Starting from aldehydes}

Since formation of an aldehyde intermediate constitutes the first step in the dehydrogenative amidation of alcohols, one might anticipate that similar processes would also readily take place starting directly from aldehydes. However, most of the ruthenium catalysts described in the previous section showed limited or no activity in the amidation of aldehydes. This discrepancy suggests that, in the amidation of alcohols, the aldehyde intermediate remains coordinated to the ruthenium center during the catalytic cycle. In addition, starting from aldehydes, imines are usually the major reaction products observed, evidencing that the dehydration of the hemiaminal intermediate prevails towards the dehydrogenation (Scheme 19). However, selective formation of amides occurs when the own structure of the substrates preclude the generation of imine or enamine derivatives (i.e. when $\mathrm{R}^{3} \neq$ $H$ or $R^{1} \neq C H R^{4} R^{5}$ in Scheme 19). Thus, in 1991, Murahashi and co-workers reported the synthesis of different benzamides by coupling benzaldehydes with secondary amines [99]. The process, promoted by $\left[\mathrm{RuH}_{2}\left(\mathrm{PPh}_{3}\right)_{4}\right]$, afforded the corresponding tertiary benzamides in moderate to good yields (Scheme 28).

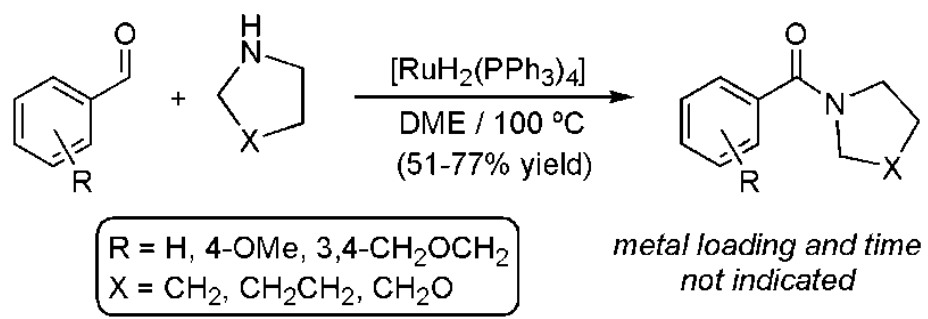

Scheme 28. Dehydrogenative amidation of aldehydes promoted by $\left[\mathrm{RuH}_{2}\left(\mathrm{PPh}_{3}\right)_{4}\right]$.

Interestingly, Hong and-coworkers evidenced that the selectivity of the coupling between aldehydes and amines can be modified by adding small amounts of an alcohol to the reaction medium (Scheme 29) [124]. Thus, with the same catalytic system, imine formation was favored in absence of alcohol, whereas amide was predominantly formed in the presence of $10 \%$ of 2-phenylethanol $\mathbf{4 5}$. Under the basic conditions employed, the alcohol presumably generates a metal-hydride via initial formation of an alkoxide-ruthenium complex and subsequent $\beta$-elimination. The authors assumed that this hydrido-derivative favors the dehydrogenation of the hemiaminal intermediate in detriment of the dehydration, thus giving rise to the desired amides as the major reaction products.

On this basis, the same authors subsequently developed an effective protocol for synthesizing amides from aldehydes using $\left[\mathrm{RuH}_{2}\left(\mathrm{PPh}_{3}\right)_{4}\right]$ [119]. In combination with the imidazolium salt $\mathbf{3 5 b}$ (see Table 1), sodium hydride and acetonitrile, this 
complex readily converted a variety of aliphatic and aromatic aldehydes into amides (Scheme 30). Further studies on the stoichiometric reactivity of $\left[\mathrm{RuH}_{2}\left(\mathrm{PPh}_{3}\right)_{4}\right]$ with $\mathrm{NaH}$ at $110^{\circ} \mathrm{C}$ suggested the formation of ruthenium(0) species during the catalytic events. This proposal was also supported by fact that the ruthenium $(0)$ complexes $\left[\mathrm{Ru}_{3}(\mathrm{CO})_{12}\right]$ and $[\mathrm{Ru}(\operatorname{cod})(\cot )]$, associated with $\mathbf{3 5} \mathbf{b}$ and $\mathrm{NaH}$, proved to be also active in the process. However, using $\left[\mathrm{Ru}_{3}(\mathrm{CO})_{12}\right]$ and $[\mathrm{Ru}(\mathrm{cod})(\mathrm{cot})]$ a large quantity of $\mathrm{NaH}(40 \mathrm{~mol} \%)$, more than that required for the generation of the NHC ligand, was needed to achieve good conversions and the reason for this still remains unclear.

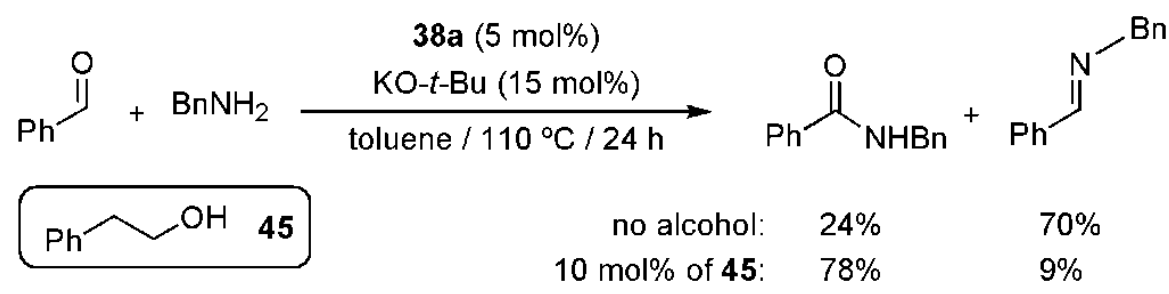

Scheme 29. Influence of an alcohol on the selectivity of the aldehyde amidation processes.

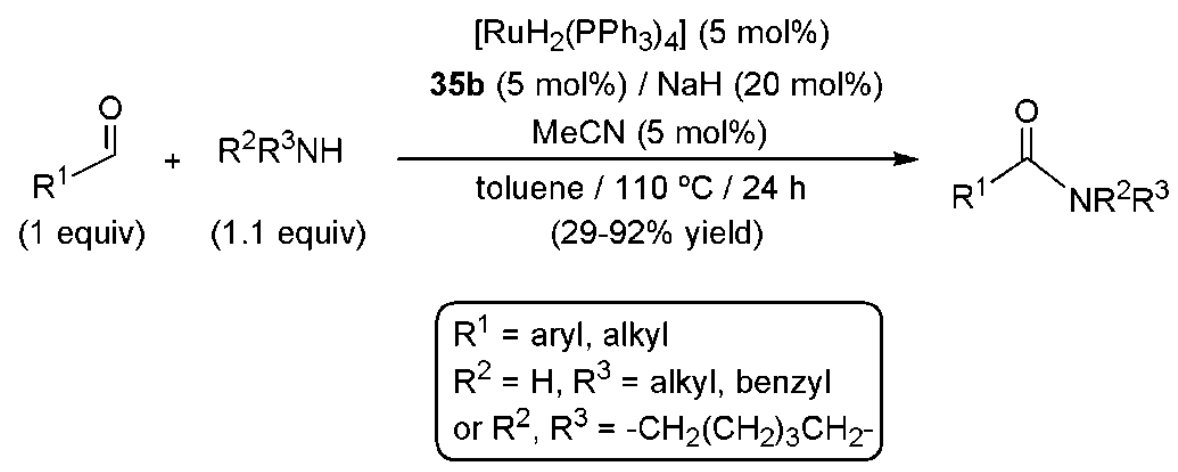

Scheme 30. [RuH $\left.{ }_{2}\left(\mathrm{PPh}_{3}\right)_{4}\right]$-promoted synthesis of amides from aldehydes.

\subsection{Starting from esters}

The direct conversion of esters into amides is a synthetically useful transformation. However, most of the methodologies developed till now usually require harsh reaction conditions, poorly compatible with sensitive substrates, and present 
a low atom economy [136]. Very recently, Milstein and co-workers demonstrated that esters can be selectively converted into amides generating molecular hydrogen as the only by-product (Scheme 31) [137]. The catalytic reactions were carried out with two equivalents of amine per ester in toluene or benzene at reflux in the presence of $0.1 \mathrm{~mol} \%$ of the dearomatized PNN-pincer ruthenium complex $[\mathrm{RuH}(\mathrm{CO})(\mathrm{PNN})](\mathbf{2 8})$ (see Scheme 21). Strikingly, both the acyl and the alkoxo units of the starting ester are involved in the amide production. Hence, to avoid mixtures of products, the process was only applied to symmetrical esters. The catalytic protocol was effective for both primary and secondary cyclic amines. In addition, the coupling of piperazine and butylbutyrate provided compound 46, which results from the bis-acylation of the diamine (Scheme 31).
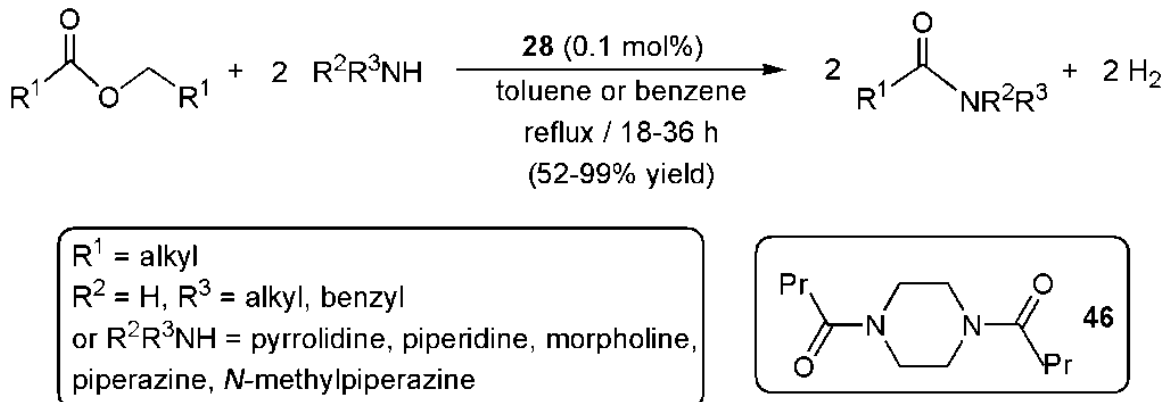

Scheme 31. Ruthenium-catalyzed synthesis of amides from esters.

The proposed mechanism for this transformation involves the initial activation of the N-H bond of the amine assisted by the dearomatized PNN-ligand (Scheme 32). Subsequent coordination of the ester to ruthenium, and coupling with the amido ligand, leads to the alkoxo intermediate $\mathbf{A}$ with concomitant release of one equivalent of amide. Subsequent $\beta$-elimination and further nucleophilic attack of the amine to the resulting aldehyde give rise to the hemiaminal $\mathbf{B}$, which evolves releasing a second equivalent of the amide. The active species is then regenerated, via deprotonation of the PNN ligand, with $\mathrm{H}_{2}$ liberation.

Shortly afterward, Hong and co-workers reported another ruthenium-based catalytic system able to promote the transformation of esters into amides [125]. Their study, which was focused on the reaction of the hexylhexanoate with the dibenzylamine, evidenced that the presence of a large amount of base favors the generation of the amide. Thus, while the use of $5 \mathrm{~mol} \%$ of $\left[\mathrm{RuCl}_{2}\left(\eta^{6}-\mathrm{C}_{6} \mathrm{H}_{6}\right)(\mathrm{IiPr})\right](\mathbf{3 8 b})$ and $20 \mathrm{~mol} \%$ of $\mathrm{KO}-t$-Bu produced the corresponding amide in only $6 \%$ yield, an increase of the base loading to $40 \mathrm{~mol} \%$ resulted in a considerable improvement of the efficiency, giving rise to a conversion of $59 \%$. 


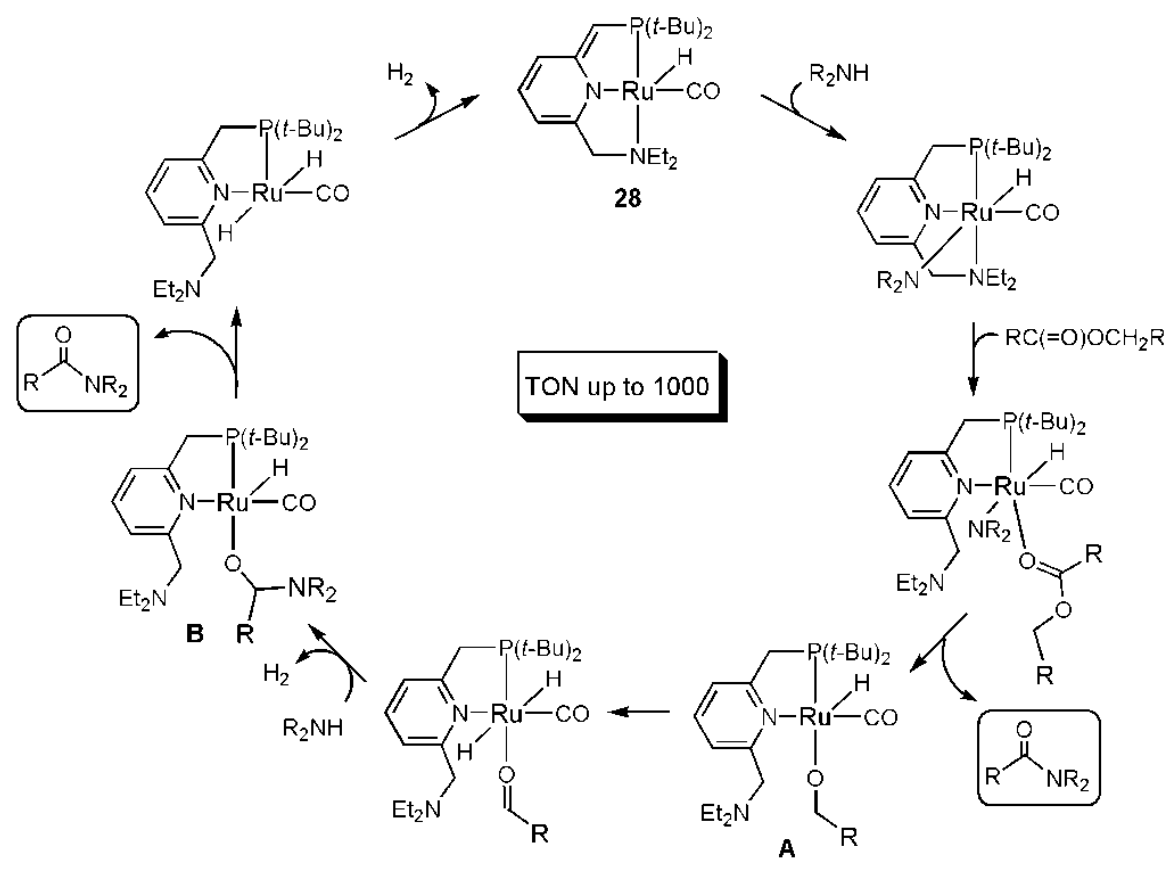

Scheme 32. Proposed mechanism for the ruthenium-catalyzed dehydrogenative amidation of esters.

\section{Other Ruthenium-Catalyzed Amide-Bond Forming Reactions}

Although amides have occasionally been reported as by-products during oxidation processes involving amines, this synthetic route remains extremely challenging $[138,139]$. The oxyfunctionalization of the $\alpha$-methylene group of amines $\mathrm{RCH}_{2} \mathrm{NH}_{2}$ usually requires the use of stoichiometric amounts of a strong oxidant, which renders mandatory the protection of the $\mathrm{NH}_{2}$ group. In this context, Mizuno and co-workers have developed a more attractive protocol based on the direct oxidation of $\mathrm{CH}_{2}$ group using air as the sole oxidant (Scheme 33) [140]. The process, performed in water under air pressure $(5 \mathrm{~atm})$ at $140^{\circ} \mathrm{C}$, could be catalyzed by different ruthenium compounds such as $\mathrm{RuCl}_{3}, \quad\left[\mathrm{Ru}(\mathrm{acac})_{3}\right], \quad\left[\mathrm{RuCl}_{2}\left(\mathrm{PPh}_{3}\right)_{3}\right]$, $\left[\left\{\operatorname{RuCl}(\mu \text {-Cl })\left(\eta^{6}-p \text {-cymene }\right)\right\}_{2}\right]$ and $\left[\mathrm{Ru}_{3}(\mathrm{CO})_{12}\right]$, but much higher selectivities were achieved with the heterogeneous system $\mathrm{Ru}(\mathrm{OH})_{\mathrm{x}} / \mathrm{Al}_{2} \mathrm{O}_{3}$. Under optimal conditions, several benzyl- or alkyl-amines produced predominantly the corresponding primary amides, with traces of the nitriles, aldehydes and carboxylic ac- 
ids being formed as by-products. Interestingly, the catalytic system could be separated by simple filtration, and reused without significant loss in activity.

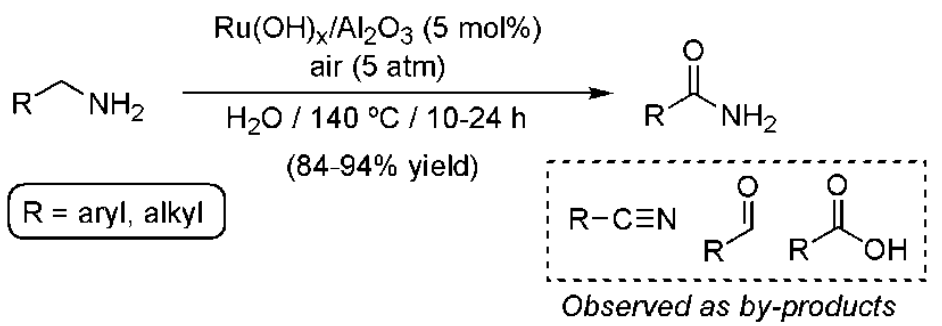

Scheme 33. Direct oxidation of primary amines into amides.

A reaction pathway involving the successive oxidative dehydrogenation of the amine into the corresponding imine and nitrile, which is subsequently hydrated, was proposed by the authors (Scheme 34) $[139,140]$. A related one-pot sequential process has also been described using the ruthenium-substituted hydroxyapatite $\left((\mathrm{RuCl})_{2} \mathrm{Ca}_{8}\left(\mathrm{PO}_{4}\right)_{6}(\mathrm{OH})_{2}\right)$ as catalyst [65].

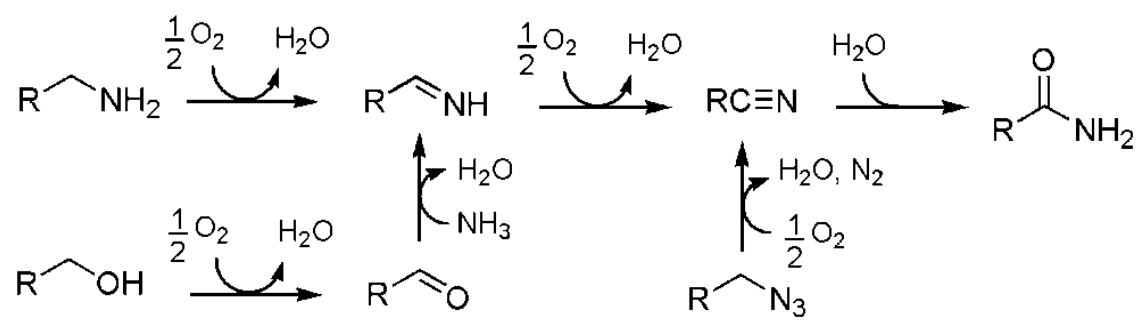

Scheme 34. Proposed pathways for amide formation through oxidative processes involving amines, azides and alcohols.

As the amines, benzylic and aliphatic azides could also be transformed into the corresponding primary amides through aerobic oxidation in water by means of $\mathrm{Ru}(\mathrm{OH})_{\mathrm{x}} / \mathrm{Al}_{2} \mathrm{O}_{3}$ [141]. Once again, the process proceeded via the formation of a nitrile intermediate (Scheme 34), with concomitant release of water and nitrogen gas. Primary amides were also synthesized from benzylic alcohols and ammonia using $\mathrm{Ru}(\mathrm{OH})_{\mathrm{x}} / \mathrm{Al}_{2} \mathrm{O}_{3}$ under air pressure [133]. In this case, the proposed mechanism is based on the following steps: $(i)$ the dehydrogenation of the alcohol into an aldehyde, (ii) the condensation of the aldehyde with $\mathrm{NH}_{3}$, (iii) oxidation of the resulting imine to generate a nitrile, and $(i v)$ final hydration of the nitrile to generate the corresponding primary amide (Scheme 34$)$. 
On other hand, unprecedented amidations of aldehydes involving nitrogen-atom transfer reactions to the acyl $\mathrm{C}\left(\mathrm{sp}^{2}\right)-\mathrm{H}$ bond have been reported by Chan and coworkers [142]. As shown in Scheme 35, the treatment of aliphatic and aromatic aldehydes with two fold excess of $\mathrm{PhI}=\mathrm{NTs}$, in the presence of $10 \mathrm{~mol} \%$ of the porphyrin-ruthenium(II) complex 47 , readily afforded the corresponding the acylsulfonamides 48 in high yield. Remarkably, chemoselective processes were observed even for aldehydes containing benzylic $\mathrm{C}-\mathrm{H}$ or $\mathrm{C}=\mathrm{C}$ bonds, known to be reactive against $\mathrm{PhI}=\mathrm{NTs}$.

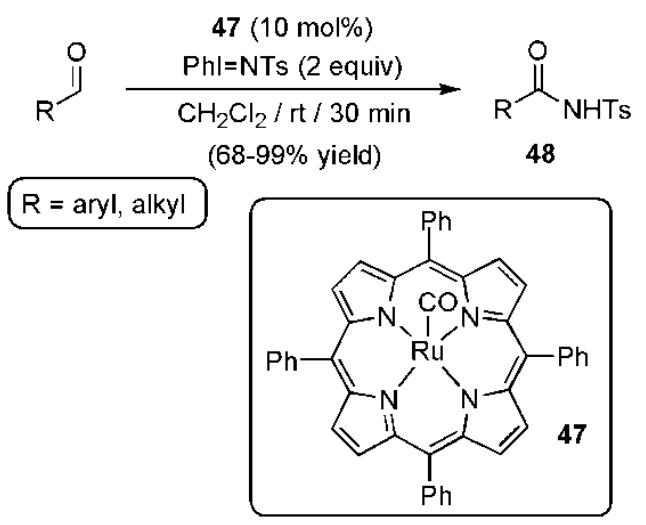

Scheme 35. Catalytic synthesis of amides through the activation of the acyl C-H bond of aldehydes.

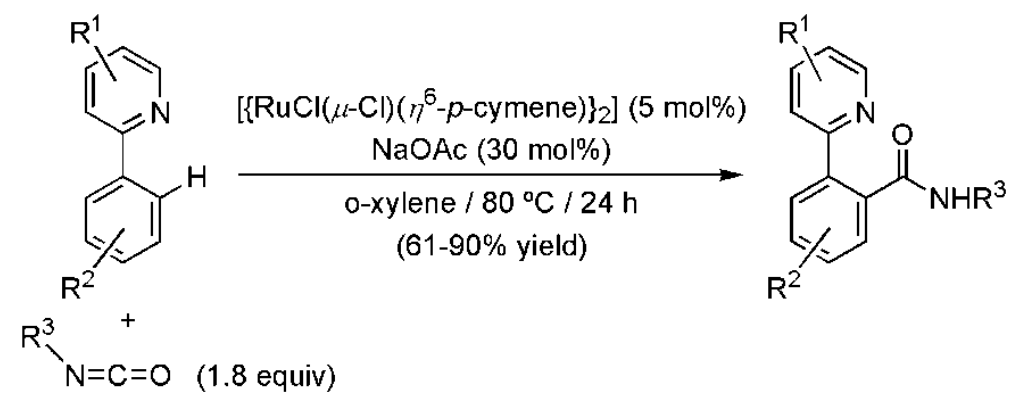

Scheme 36. Catalytic formation of amides by isocyanate insertion into C-H bonds.

$\mathrm{C}-\mathrm{H}$ bond activation was also involved in the reactions of 2-arylpyridines with isocyanates promoted by the dimeric precursor $\left[\left\{\mathrm{RuCl}(\mu-\mathrm{Cl})\left(\eta^{6}-p \text {-cymene }\right)\right\}_{2}\right]$ (Scheme 36) [143]. The process was satisfactorily applied to the synthesis of a wide range (22 examples) of pyridyl-functionalized benzamides. Arylpyridines 
with both electron-donating and electron-withdrawing substituents were suitable substrates, and classical organic functional groups such as ether, halogen, aldehyde or cyano were tolerated. Worthy of note, when the aryl ring presented an unsymmetrical substitution pattern, the $\mathrm{C}-\mathrm{H}$ activation took place at the less hindered position selectively.

Metal-catalyzed reductive acylation reactions of ketoximes into $\mathrm{N}$-acetyl enamides are known for long time [144]. Recently, an example promoted by the ruthenium dimer $\left[\left\{\mathrm{RuCl}(\mu-\mathrm{Cl})\left(\eta^{6}-p \text {-cymene }\right)\right\}_{2}\right]$ has been described (Scheme 37$)$ [145]. Remarkably, the process was successfully applied to the synthesis of 49, a key intermediate in the preparation of leukocyte elastase inhibitor DMP 777.

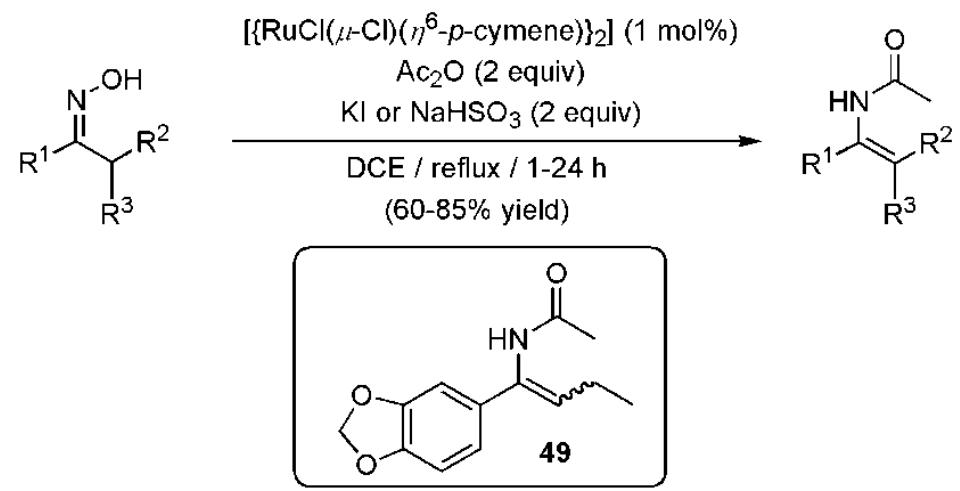

Scheme 37. Ruthenium-catalyzed reductive acylation of ketoximes.

\section{Conclusion}

In the last years there has been an increasing interest in the adoption of catalytic methods for amide formation since, compared to classical amide couplings involving carboxylic acids and their derivatives with amines, they are more environmentally sustainable and cost effective. Ruthenium catalysts have played a key role in advancing this field, and in many cases have led to pioneer transformations. Throughout this chapter we have tried to highlight the utility and the huge potential of these catalysts. The range of methods currently available allows synthetic chemists choosing from a wide variety of starting materials for the construction of amide bonds (nitriles, aldoximes, primary alcohols, aldehydes, esters, etc.). Obviously the field remains open and hopefully most active catalysts for known processes, as well as new innovative transformations, will see the light in the coming years. We hope that reading this chapter serve as a catalyst and inspire future developments. 
Acknowledgments Our research in the field of amide bond forming reactions was supported by MINECO of Spain (projects CTQ2006-08485/BQU, CTQ2010-14796/BQU and CSD2007-00006). We heartily wish to thank our co-workers Dr. Javier Francos and Dr. Rocío García-Álvarez for their strong commitment to this chemistry.

\section{References}

[1] Zabicky J (1970) The chemistry of amides. Wiley-Interscience, New York

[2] Greenberg A, Breneman CM, Liebman (2000) The amide linkage: Structural significance in chemistry, biochemistry and materials science. John Wiley \& Sons, New York

[3] Dugger RW, Ragan JA, Ripin DHB (2005) Survey of GMP bulk reactions run in a research facility between 1985 and 2002. Org Process Res Dev 9:253

[4] Carey JS, Laffan D, Thomson C, Williams TM (2006) Analysis of the reactions used for the preparation of drug candidate molecules. Org Biomol Chem 4:2337

[5] Ghose AK, Viswanadhan VN, Wendoloski JJ (1999) A knowledge-based approach in designing combinatorial or medicinal chemistry libraries for drug discovery. 1. A qualitative and quantitative characterization of known drug databases. J Comb Chem 1:55

[6] Montalbetti CAGN, Falque V. (2005) Amide bond formation and peptide coupling. Tetrahedron 61:10827

[7] Valeur E, Bradley M (2009) Amide bond formation: Beyond the myth of coupling reagents. Chem Soc Rev 38:606

[8] Constable DJC, Dunn PJ, Hayler JD, Humphrey GR, Leazer JL, Linderman RJ, Lorenz K, Manley J, Pearlman BA, Wells A, Zaks A, Zhang TY (2007) Key green chemistry research areas - A perspective from pharmaceutical manufacturers. Green Chem 9:411

[9] Allen CL, Williams JMJ (2011) Metal-catalysed approaches to amide bond formation. Chem Soc Rev 40:3405

[10] Pattabiraman VR, Bode JW (2011) Rethinking amide bond synthesis. Nature 480:471

[11] Roy S, Roy S, Gribble GW (2012) Metal-catalyzed amidation. Tetrahedron 68:9867

[12] García-Álvarez R, Crochet P, Cadierno V (2013) Metal-catalyzed amide bond forming reactions in an environmentally friendly aqueous medium: Nitrile hydrations and beyond. Green Chem 15:46

[13] Bode JW (2013) Reinventing amide bond formation. Top Organomet Chem 44:13

[14] Singh C, Kumar V, Sharma U, Kumar N, Singh B (2013) Emerging catalytic methods for amide synthesis. Curr Org Synth 10:241

[15] Yamada H, Kobayashi M (1996) Nitrile hydratase and its application to industrial production of acrylamide. Biosci Biotech Biochem 60:1391

[16] Tao J, Xu JH (2009) Biocatalysis in development of green pharmaceutical processes. Curr Opin Chem Biol 13:45

[17] Sanchez S, Demain AL (2011) Enzymes and bioconversions of industrial, pharmaceutical, and biotechnological significance. Org Process Res Dev 15:224

[18] Li B, Su J, Tao J (2011) Enzyme and process development for production of nicotinamide. Org Process Res Dev 15:291

[19] Kopylovich MN, Kukushkin VY, Haukka M, Fraústo da Silva JJR, Pombeiro AJL (2002) Zinc(II)/ketoxime system as a simple and efficient catalyst for hydrolysis of organonitriles. Inorg Chem 41:4789 and references cited therein

[20] Kukushkin VY, Pombeiro AJL (2002) Additions to metal-activated organonitriles. Chem Rev 102:1771 
[21] Kukushkin VY, Pombeiro AJL (2005) Metal-mediated and metal-catalyzed hydrolysis of nitriles. Inorg Chim Acta 358:1

[22] Ahmed TJ, Knapp SMM, Tyler DR (2011) Frontiers in catalytic nitrile hydration: Nitrile and cyanohydrin hydration catalyzed by homogeneous organometallic complexes. Coord Chem Rev 255:949

[23] Murahashi SI, Sasao S, Saito E, Naota T (1992) Ruthenium-catalyzed hydration of nitriles and transformation of $\delta$-keto nitriles to ene-lactams. J Org Chem 57:2521

[24] Murahashi SI, Sasao S, Saito E, Naota T (1993) Ruthenium-catalyzed hydration of nitriles and transformation of $\delta$-keto nitriles to ene-lactams: Total synthesis of (-) pumiliotoxin C. Tetrahedron 49:8805

[25] Murahashi SI, Naota T (1996) A new way for efficient catalysis by using low valent ruthenium complexes as redox Lewis acid and base catalysts. Bull Chem Soc Jpn 69:1805

[26] Murahashi SI, Takaya H (2000) Low-valent ruthenium and iridium hydride complexes as alternatives to Lewis acid and base catalysts. Acc Chem Res 33:225

[27] Fung WK, Huang X, Man ML, Ng SM, Hung MY, Lin Z, Lau CP (2003) Dihydrogenbond-promoted catalysis: Catalytic hydration of nitriles with the indenylruthenium hydride complex $\left(\eta^{5}-\mathrm{C}_{9} \mathrm{H}_{7}\right) \mathrm{Ru}(\mathrm{dppm}) \mathrm{H}(\mathrm{dppm}=$ bis(diphenylphosphino)methane). J Am Chem Soc 125:11539

[28] Leung CW, Zheng W, Wang D, Ng SM, Yeung CH, Zhou Z, Lin Z, Lau CP (2007) Catalytic H/D exchange between organic compounds and $\mathrm{D}_{2} \mathrm{O}$ with $\mathrm{TpRu}\left(\mathrm{PPh}_{3}\right)\left(\mathrm{CH}_{3} \mathrm{CN}\right) \mathrm{H} \quad(\mathrm{Tp}=$ hydro(trispyrazolyl)borate). Reaction of $\mathrm{TpRu}\left(\mathrm{PPh}_{3}\right)\left(\mathrm{CH}_{3} \mathrm{CN}\right) \mathrm{H}$ with water to form acetamido complex $\mathrm{TpRu}\left(\mathrm{PPh}_{3}\right)\left(\mathrm{H}_{2} \mathrm{O}\right)\left(\mathrm{NHC}(\mathrm{O}) \mathrm{CH}_{3}\right)$. Organometallics 26:1924

[29] Leung CW, Zheng W, Zhou Z, Lin Z, Lau CP (2008) Mechanism of catalytic hydration of nitriles with hydrotris(pyrazolyl)borato (Tp) ruthenium complexes. Organometallics 27:4957

[30] Li T, Bergner I, Haque FN, Zimmer-De Iuliis M, Song D, Morris RH (2007) Hydrogenation of benzonitrile to benzylamine catalyzed by ruthenium hydride complexes with P-NH-NH-P tetradentate ligands: Evidence for a hydridic-protonic outer sphere mechanism. Organometallics 26:5940

[31] Yi CS, Zeczycki TN, Lindeman SV (2008) Kinetic, spectroscopic, and X-ray crystallographic evidence for the cooperative mechanism of the hydration of nitriles catalyzed by a tetranuclear ruthenium- $\mu$-oxo- $\mu$-hydroxo complex. Organometallics 27:2030

[32] Utsunomiya M, Takahashi K, Oshiki T, Takai K (2004) New ruthenium complex, method for producing the same and method for producing amide compound using the same. Jpn Kokai Tokkyo Koho JP2004269522

[33] Oshiki T, Yamashita H, Sawada K, Utsunomiya M, Takahashi K, Takai K (2005) Dramatic rate acceleration by a diphenyl-2-pyridylphosphine ligand in the hydration of nitriles catalyzed by $\mathrm{Ru}(\mathrm{acac})_{2}$ complexes. Organometallics 24:6287

[34] Oshiki T, Hyodo I, Ishizuka A (2005) Highly reactive bifunctional chemical catalysts for the hydration of nitriles. J Synth Org Chem Jpn 68:41

[35] Oshiki T, Takai K (2008) Method for producing amide compound and catalyst used for the same method. Jpn Kokai Tokkyo Koho JP2008088153

[36] Muranaka M, Hyodo I, Okumura W, Oshiki T (2011) 2-Diphenylphosphanyl-4pyridyl(dimethyl)amine as an effective ligand for the ruthenium(II) complex catalyzed homogeneous hydration of nitriles under neutral conditions. Catal Today 164:552

[37] Šmejkal T, Breit B (2007) Self-assembled bidentate ligands for ruthenium-catalyzed hydration of nitriles. Organometallics 26:2461

[38] García-Álvarez R, García-Garrido, SE, Díez J, Crochet P, Cadierno V (2012) Areneruthenium(II) and bis(allyl)-ruthenium(IV) complexes containing 2- 
(diphenylphosphanyl)pyridine ligands: Potential catalysts for nitrile hydration reactions?. Eur J Inorg Chem:4218

[39] García-Álvarez R, Díez J, Crochet P, Cadierno V (2010) Arene-ruthenium(II) complexes containing amino-phosphine ligands as catalysts for nitrile hydration reactions. Organometallics 29:3955

[40] Cadierno V, Francos J, Gimeno J (2008) Selective ruthenium-catalyzed hydration of nitriles to amides in pure aqueous medium under neutral conditions. Chem Eur $\mathrm{J}$ 14:6601

[41] Cadierno V, Díez J, Francos J, Gimeno J (2010) Bis(allyl)ruthenium(IV) complexes containing water-soluble phosphane ligands: Synthesis, structure, and application as catalysts in the selective hydration of organonitriles into amides. Chem Eur J 16:9808

[42] Lee WC, Frost BJ (2012) Aqueous and biphasic nitrile hydration catalyzed by a recyclable $\mathrm{Ru}(\mathrm{II})$ complex under atmospheric conditions. Green Chem 14:62

[43] Frost BJ, Lee WC (2013) Nitrile hydration catalyzed by recyclable ruthenium complexes. US Pat Appl US2013/0096344

[44] Lee WC, Sears JM, Enow RA, Eads K, Krogstad DA, Frost BJ (2013) Hemilabile $\beta$ aminophosphine ligands derived from 1,3,5-triaza-7-phosphaadamantane: Application in aqueous ruthenium catalyzed nitrile hydration. Inorg Chem 52:1737

[45] García-Álvarez R, Zablocka M, Crochet P, Duhayon C, Majoral JP, Cadierno V (2013) Thiazolyl-phosphine hydrochloride salts: Effective auxiliary ligands for rutheniumcatalyzed nitrile hydration reactions and related amide bond forming processes in water. Green Chem 15:2447

[46] García-Álvarez R, Francos J, Crochet P, Cadierno V (2011) Ibuprofenamide: A convenient method of synthesis by catalytic hydration of 2-(4-isobutylphenyl)propionitrile in pure aqueous medium. Tetrahedron Lett 52:4218

[47] García-Álvarez R, Díez J, Crochet P, Cadierno V (2011) Arene-ruthenium(II) complexes containing inexpensive tris(dimethylamino)phosphine: Highly efficient catalysts for the selective hydration of nitriles to amides. Organometallics 30:5442

[48] Knapp SMM, Sherbow TJ, Juliette JJ, Tyler DR (2012) Cyanohydrin hydration with $\left[\mathrm{Ru}\left(\eta^{6}\right.\right.$-p-cymene $\left.) \mathrm{Cl}_{2} \mathrm{PR}_{3}\right]$ complexes. Organometallics 31:2941

[49] Knapp SMM, Sherbow TJ, Yelle RB, Zakharov LN, Juliette JJ, Tyler DR (2013) Mechanistic investigations and secondary coordination sphere effects in the hydration of nitriles with $\left[\mathrm{Ru}\left(\eta^{6}\right.\right.$-arene $\left.) \mathrm{Cl}_{2} \mathrm{PR}_{3}\right]$ complexes. Organometallics 32:824

[50] Knapp SMM, Sherbow TJ, Yelle RB, Juliette JJ, Tyler DR (2013) Catalytic nitrile hydration with $\left[\mathrm{Ru}\left(\eta^{6}-p\right.\right.$-cymene $\left.) \mathrm{Cl}_{2}\left(\mathrm{PR}_{2} \mathrm{R}^{\prime}\right)\right]$ complexes: Secondary coordination sphere effects with phosphine oxide and phosphinite ligands. Organometallics 32:3744

[51] Oshiki T, Muranaka M (2012) Metal complex compound and amide production method that utilizes said metal complex compound. PCT Int Appl WO2012/017966

[52] Ashraf SM, Berger I, Nazarov AA, Hartinger CG, Koroteev MP, Nifant'ev EE, Keppler BK (2008) Phosphite-derivatized ruthenium-carbohydrate complexes in the catalytic hydration of nitriles. Chem Biodiversity 5:1640

[53] Ashraf SM, Kandioller W, Mendoza-Ferri MG, Nazarov AA, Hartinger CG, Keppler BK (2008) The hydration of chloroacetonitriles catalyzed by mono- and dinuclear $\mathrm{Ru}^{\mathrm{II}}$ and Os ${ }^{\mathrm{II}}$-arene complexes. Chem Biodiversity 5:2060

[54] Martín M, Horváth H, Sola E, Kathó Á, Joó F (2009) Water-soluble triisopropylphosphine complexes of ruthenium(II): Synthesis, equilibria, and acetonitrile hydration. Organometallics 28:561

[55] Cavarzan A, Scarso A, Strukul G (2010) Efficient nitrile hydration mediated by $\mathrm{Ru}^{\mathrm{II}}$ catalysts in micellar media. Green Chem 12:790 
[56] Ferrer Í, Rich J, Fontrodona X, Rodríguez M, Romero I (2013) Ru(II) complexes containing dmso and pyrazolyl ligands as catalysts for nitrile hydration in environmentally friendly media. Dalton Trans 42:13461

[57] Kumar D, Masitas CA, Nguyen TN, Grapperhaus GA (2013) Bioinspired catalytic nitrile hydration by dithiolato, sulfinato/thiolato, and sulfenato/sulfinato ruthenium complexes. Chem Commun 49:294

[58] Ammar HB, Miao X, Fischmeister C, Toupet L, Dixneuf PH (2010) Bidentate oxazoline-imine ruthenium(II) complexes: Intermediates in the methanolysis/hydration of nitrile groups. Organometallics 29:4234

[59] Kamezaki S, Akiyama S, Kayaki Y, Kuwata S, Ikariya T (2010) Asymmetric nitrilehydration with bifunctional ruthenium catalysts bearing chiral $\mathrm{N}$-sulfonyldiamine ligands. Tetrahedron Asymmetry 21:1169

[60] Yamaguchi K, Matsushita M, Mizuno N (2004) Efficient hydration of nitriles to amides in water, catalyzed by ruthenium hydroxide supported on alumina. Angew Chem Int Ed 43:1576

[61] Polshettiwar V, Varma RS (2009) Nanoparticle-supported and magnetically recoverable ruthenium hydroxide catalyst: Efficient hydration of nitriles to amides in aqueous medium. Chem Eur J 15:1582

[62] Baig RBN, Varma RS (2013) Organic synthesis via magnetic attraction: Benign and sustainable protocols using magnetic nanoferrites. Green Chem 15:398

[63] Baig RBN, Varma RS (2012) A facile one-pot synthesis of ruthenium hydroxide nanoparticles on magnetic silica: Aqueous hydration of nitriles to amides. Chem Commun 48:6220

[64] García-Garrido SE, Francos J, Cadierno V, Basset JM, Polshettiwar V (2011) Chemistry by nanocatalysis: First example of a solid-supported RAPTA complex for organic reactions in aqueous medium. ChemSusChem 4:104

[65] Mori K, Yamaguchi K, Mizugaki T, Ebitani K, Kaneda K (2001) Catalysis of a hydroxyapatite-bound $\mathrm{Ru}$ complex: Efficient heterogeneous oxidation of primary amines to nitriles in the presence of molecular oxygen. Chem Commun:461

[66] Prakash GKS, Munoz SB, Papp A, Masood K, Bychinskaya I, Mathew T, Olah GA (2012) Nafion-Ru: A sustainable catalyst for selective hydration of nitriles to amides. Asian J Org Chem 1:146

[67] Kurata T, Tamaru A, Murata Y, Nagashima S, Okano T, Ohfucchi K (1973) Unsaturated amides. Jpn Kokai Tokkyo Koho JP48054021

[68] Mizuno T (2005) Method for producing amide compounds by hydration reaction of nitrile compounds. Jpn Kokai Tokkyo Koho JP2005170821

[69] Oshiki T, Ishizuka A (2009) Method for producing amide compound and catalyst to be used therein. Jpn Kokai Tokkyo Koho JP2009214099

[70] Kumar S, Das P (2013) Solid-supported ruthenium(0): An efficient heterogeneous catalyst for hydration of nitriles to amides under microwave irradiation. New J Chem 37:2987

[71] Cobley CJ, van den Heuvel M, Abbadi A, de Vries JG (2000) Platinum catalysed hydrolytic amidation of unactivated nitriles. Tetrahedron Lett 41:2467

[72] van Dijk AJM, Duchateau R, Hensen EJM, Meuldijk J, Koning CE (2007) Polyamide synthesis from 6-aminocapronitrile, part 2: Heterogeneously catalyzed nitrile hydrolysis with consecutive amine amidation. Chem Eur J 13:7673

[73] Allen CL, Lapkin AA, Williams JMJ (2009) An iron-catalysed synthesis of amides from nitriles and amines. Tetrahedron Lett 50:4262

[74] Tamura M, Tonomura T, Shimizu KI, Satsuma A (2012) $\mathrm{CeO}_{2}$-catalyzed one-pot selective synthesis of $N$-alkyl amides from nitriles, amines and water. Appl Catal A Gen 417-418:6 
[75] Davulcu S, Allen CL, Milne K, Williams JMJ (2013) Catalytic conversion of nitriles into secondary- and tertiary amides. ChemCatChem 5:435

[76] Li X, Li Z, Deng H, Zhou X (2013) An efficient protocol for the preparation of amides by copper-catalyzed reactions between nitriles and amines in water. Tetrahedron Lett $54: 2212$

[77] Ghodsinia SSE, Akhlaghinia B, Safaei E, Eshghi H (2013) Green and selective synthesis of $N$-substituted amides using water-soluble porphyrazinato copper(II) catalyst. J Braz Chem Soc 24:895

[78] Murahashi SI, Naota T, Saito E (1986) Ruthenium-catalyzed amidation of nitriles with amines. A novel, facile route to amides and polyamides. J Am Chem Soc 108:7846

[79] van Dijk AJM, Heyligen T, Duchateau R, Meuldijk J, Koning CE (2007) Polyamide synthesis from 6-aminocapronitrile, part 1: $\mathrm{N}$-alkyl amide formation by amine amidation of a hydrolyzed nitrile. Chem Eur J 13:7664

[80] Field L, Hughmark PB, Shumaker SH, Marshall WS (1961) Isomerization of aldoximes to amides under substantially neutral conditions. J Am Chem Soc 83:1983

[81] Park S, Choi Y, Han H, Yang SH, Chang S (2003) Rh-catalyzed one-pot and practical transformation of aldoximes to amides. Chem Commun:1936

[82] Allen CL, Lawrence R, Emmett L, Williams JMJ (2011) Mechanistic studies into metal-catalyzed aldoxime to amide rearrangement. Adv Synth Catal 353:3262

[83] Okano T, Fujiwara K, Konishi H, Kiji J (1982) Application of the water-gas shift reaction. III. Reduction of oxidized nitrogen compounds with $\mathrm{CO}$ and $\mathrm{H}_{2} \mathrm{O}$ catalyzed by $\left[\mathrm{Ru}(\mathrm{cod}) \mathrm{py}_{4}\right]\left(\mathrm{BPh}_{4}\right)_{2}$. Bull Chem Soc Jpn 55:1975

[84] Owston NA, Parker AJ, Williams JMJ (2007) Highly efficient ruthenium-catalyzed oxime to amide rearrangement. Org Lett 9:3599

[85] Gnanamgari D, Crabtree RH (2009) Terpyridine ruthenium-catalyzed one-pot conversion of aldehydes into amides. Organometallics 28:922

[86] Kumar P, Singh AK, Pandey R, Pandey DS (2011) Bio-catalysts and catalysts based on ruthenium(II) polypyridyl complexes imparting diphenyl-(2-pyridyl)-phosphine as a co-ligand. J Organomet Chem 696:3454

[87] Raja N, Raja MU, Ramesh R (2012) Ruthenium(II) NNO pincer type catalyst for the conversion of aldehydes to amides. Inorg Chem Commun 19:51

[88] Prabhu RN, Ramesh R (2012) Ruthenium(II) carbonyl complexes containing benzhydrazone ligands: Synthesis, structure and facile one-pot conversion of aldehydes to amides. RSC Adv 2:4515

[89] Manikandan R, Prakash G, Kathirvel R, Viswanathamurthi P (2013) Ruthenium(II) carbonyl complexes bearing quinoline-based NNO tridentate ligands as catalyst for onepot conversion of aldehydes to amides and $O$-allylation of phenols. Spectrochim Acta A 116:501

[90] Hull JF, Hilton ST, Crabtree RH (2010) A simple Ru catalyst for the conversion of aldehydes or oximes to primary amides. Inorg Chim Acta 363:1243

[91] García-Álvarez R, Díaz-Álvarez AE, Borge J, Crochet P, Cadierno V (2012) Ruthenium-catalyzed rearrangement of aldoximes to primary amides in water. Organometallics $31: 6482$

[92] García-Álvarez R, Díaz-Álvarez AE, Crochet P, Cadierno V (2013) Rutheniumcatalyzed one-pot synthesis of primary amides from aldehydes in water. RSC Adv 3:5889

[93] Li F, Qu P, Ma J, Zou X, Sun C (2013) Tandem synthesis of $N$-alkylated amides from aldoximes and alcohols by using a Ru/Ir dual-catalyst system. ChemCatChem 5:2178

[94] Chen C, Hong SH (2011) Oxidative amide synthesis directly from alcohols with amines. Org Biomol Chem 9:20 
[95] Gunanathan C, Milstein D (2013) Applications of acceptorless dehydrogenation and related transformations in chemical synthesis. Science 341:249

[96] Dobereiner GE, Crabtree RH (2010) Dehydrogenation as a substrate-activating strategy in homogeneous transition-metal catalysis. Chem Rev 110:681

[97] Gnanaprakasam B, Zhang J, Milstein D (2010) Direct synthesis of imines from alcohols and amines with liberation of $\mathrm{H}_{2}$. Angew Chem Int Ed 49:1468

[98] Marr AC (2012) Organometallic hydrogen transfer and dehydrogenation catalysts for the conversion of bio-renewable alcohols. Catal Sci Technol 2:279

[99] Naota T, Murahashi SI (1991) Ruthenium-catalyzed transformations of amino alcohols to lactams. Synlett:693

[100] Fujita K-I, Takahashi Y, Owaki M, Yamamoto K, Yamaguchi R (2004) Synthesis of five-, six-, and seven-membered ring lactams by $\mathrm{Cp} * \mathrm{Rh}$ complex-catalyzed oxidative $\mathrm{N}$ heterocyclization of amino alcohols. Org Lett 6:2785

[101] Gunanathan C, Ben-David Y, Milstein D (2007) Direct synthesis of amides from alcohols and amines with liberation of $\mathrm{H}_{2}$. Science 317:790

[102] Gunanathan C, Milstein D (2011) Bond activation by metal-ligand cooperation: Design of "green" catalytic reactions based on aromatization-dearomatization of pincer complexes. Top Organomet Chem 37:55

[103] Gunanathan C, Milstein D (2011) Metal-ligand cooperation by aromatizationdearomatization: A new paradigm in bond activation and "green" catalysis. Acc Chem Res 44:588

[104] Milstein D (2010) Discovery of environmentally benign catalytic reactions of alcohols catalyzed by pyridine-based pincer Ru complexes, based on metal-ligand cooperation. Top Catal 53:915

[105] Li H, Wang X, Huang F, Lu G, Jiang J, Wang ZX (2011) Computational study on the catalytic role of pincer ruthenium(II)-PNN complex in directly synthesizing amide from alcohol and amine: The origine of selectivity of amide over ester and imine. Organometallics 30:5233

[106] Zeng G, Li S (2011) Insights into dehydrogenative coupling of alcohols and amines catalyzed by a (PNN)-Ru(II) hydride complex: Unusual metal-ligand cooperation. Inorg Chem 50:10572

[107] Cho D, Ko KC, Lee JY (2013) Catalytic mechanism for the ruthenium-complexcatalyzed synthesis of amides from alcohols and amines: A DFT study. Organometallics 32:4571

[108] Zeng H, Guan Z (2011) Direct synthesis of polyamides via catalytic dehydrogenation of diols and diamines. J Am Chem Soc 133:1159

[109] Gnanaprakasam B, Balaraman E, Gunanathan C, Milstein D (2012) Synthesis of polyamides from diols and diamines with liberation of $\mathrm{H}_{2}$. J Poly Sci Part A: Polymer Chem 50:1755

[110] Milstein D, Balaraman E, Gunanathan C, Gnanaprakasam B, Zhang J (2012) Novel ruthenium complexes and their uses in processes for formation and/or hydrogenation of esters, amides and derivatives thereof. PCT Int Appl WO2012052996

[111] Gnanaprakasam B, Balaraman E, Ben-David Y, Milstein D (2011) Synthesis of peptides and pyrazines from $\beta$-amino alcohols through extrusion of $\mathrm{H}_{2}$ catalyzed by ruthenium pincer complexes: Ligands-controlled selectivity. Angew Chem Int Ed 50:12240

[112] Zweifel T, Naubron JV, Grützmacher H (2009) Catalyzed dehydrogenative coupling of primary alcohols with water, methanol, or amines. Angew Chem Int Ed 48:559

[113] Shimizu KI, Ohshima K, Satsuma A (2009) Direct dehydrogenative amide synthesis from alcohols and amines catalyzed by $\gamma$-alumina supported silver cluster. Chem Eur J 15:9977 
[114] Nordstrøm LU, Vogt H, Madsen R (2008) Amide synthesis from alcohols and amines by the extrusion of dihydrogen. J Am Chem Soc 130:17672

[115] Ghosh SC, Muthaiah S, Zhang Y, Xu X, Hong SH (2009) Direct amide synthesis from alcohols and amines by phosphine-free ruthenium catalyst systems. Adv Synth Catal 351:2643

[116] Ghosh SC, Hong SH (2010) Simple $\mathrm{RuCl}_{3}$-catalyzed amide synthesis from alcohols and amines. Eur J Org Chem:4266

[117] Dam JH, Osztrovszky G, Nordstrøm LU, Madsen R (2010) Amide synthesis from alcohols and amines catalyzed by ruthenium $N$-heterocyclic carbene complexes. Chem Eur J 16:6820

[118] Zhang J, Senthilkumar M, Ghosh SC, Hong SH (2010) Synthesis of cyclic imides from simple diols. Angew Chem Int Ed 49:6391

[119] Muthaiah S, Ghosh SC, Jee JE, Chen C, Zhang J, Hong SH (2010) Direct amides synthesis from either alcohols or aldehydes with amines: Activity of Ru(II) hydride and $\mathrm{Ru}(0)$ complexes. J Org Chem 75:3002

[120] Makarov IS, Fristrup P, Madsen R (2012) Mechanistic investigation of ruthenium- $N$ heterocyclic-carbene-catalyzed amidation of amines with alcohols. Chem Eur J 18:15683

[121] Prechtl MHG, Wobser K, Theyssen N, Ben-David Y, Milstein D, Leitner W (2012) Direct coupling of alcohols to form esters and amides with evolution of $\mathrm{H}_{2}$ using in situ formed ruthenium catalysts. Catal Sci Technol 2:2039

[122] Pingen D, Vogt D (2014) Amino-alcohols cyclization: Selective synthesis of lactams and cyclic amines from amino-alcohols. Catal Sci Technol 4:47

[123] Watson AJA, Maxwell AC, Williams JMJ (2009) Ruthenium-catalyzed oxidation of alcohols into amides. Org Lett 11:2667

[124] Zhang Y, Chen C, Ghosh SC, Li Y, Hong SH (2010) Well-defined N-heterocyclic carbene based ruthenium catalysts for direct amide synthesis from alcohols and amines. Organometallics 29:1374

[125] Chen C, Zhang Y, Hongs H (2011) N-heterocyclic carbene based rutheniumcatalyzed direct amide synthesis from alcohols and secondary amines: Involvement of esters. J Org Chem 76:10005

[126] Prades A, Peris E, Albrecht M (2011) Oxidations and oxidative couplings catalyzed by triazolylidene ruthenium complexes. Organometallics 30:1162

[127] Schley N, Dobereiner GE, Crabtree RH (2011) Oxidative synthesis of amides and pyrroles via dehydrogenative alcohol oxidation by ruthenium diphosphine diamine complexes. Organometallics 30:4174

[128] Nova A, Balcells D, Schley ND, Dobereiner GE, Crabtree RH, Eisenstein O (2010) An experimental-theoretical study of the factors that affect the switch between ruthenium-catalyzed dehydrogenative amide formation versus amine alkylation. Organometallics 29:6548

[129] Srimani D, Balaraman E, Hu P, Ben-David Y, Milstein D (2013) Formation of tertiary amides and dihydrogen by dehydrogenative coupling of primary alcohols with secondary amines catalyzed by ruthenium bipyridine-based pincer complexes. Adv Synth Catal 355:2525

[130] Ortega N, Richter C, Glorius F (2013) $\mathrm{N}$-formylation of amines by methanol activation. Org Lett 15:1776

[131] Malineni J, Merkens C, Keul H, Möller M (2013) An efficient $N$-heterocyclic carbene based ruthenium-catalyst: Application towards the synthesis of esters and amides. Catal Commun 40:80 
[132] Wang Y, Zhu D, Tang L, Wang S, Wang Z (2011) Highly efficient amide synthesis from alcohols and amines by virtue of a water-soluble gold/DNA catalyst. Angew Chem Int Ed 50:8917

[133] Oishi T, Yamaguchi K, Mizuno N (2010) An efficient one-pot synthesis of nitriles from alcohols or aldehydes with $\mathrm{NH}_{3}$ catalyzed by a supported ruthenium hydroxide. Top Catal 53:479

[134] Fu Z, Lee J, Kang B, Hong SH (2012) Dehydrogenative amide synthesis: Azide as a nitrogen source. Org Lett 14:6028

[135] Kang B, Fu Z, Hong SH (2013) Ruthenium-catalyzed redox-neutral and single-step amide synthesis from alcohol and nitrile with complete atom economy. J Am Chem Soc 135:11704

[136] Varma RS, Naicker KP (1999) Solvent-free synthesis of amides from non-enolizable esters and amines using microwave irradiation. Tetrahedron Lett 40:6177 and references cited therein

[137] Gnanaprakasam B, Milstein D (2011) Synthesis of amides from esters and amines with liberation of $\mathrm{H}_{2}$ under neutral conditions. J Am Chem Soc 133:1682

[138] Yamaguchi K, Mizuno N (2010) Green functional group transformations by supported ruthenium hydroxide catalysts. Synlett:2365

[139] Schümperli MT, Hammond C, Hermans I (2012) Developments in the aerobic oxidation of amines. ACS Catal 2:1108

[140] Kim JW, Yamaguchi K, Mizuno N (2008) Heterogeneously catalyzed efficient oxygenation of primary amines to amides by a supported ruthenium hydroxide catalyst. Angew Chem Int Ed 47:9249

[141] He J, Yamaguchi K, Mizuno N (2011) Aerobic oxidative transformation of primary azides to nitriles by ruthenium hydroxide catalyst. J Org Chem 76:4606

[142] Chang JWW, Chan PWH (2008) Highly efficient ruthenium(II) porphyrin catalyzed amidation of aldehydes. Angew Chem Int Ed 47:1138

[143] Muralirajan K, Parthasarathy K, Cheng CH (2012) Ru(II)-catalyzed amidation of 2 arylpyridines with isocyanates via $\mathrm{C}-\mathrm{H}$ activation. Org Lett 14:4262

[144] Tang W, Capacci A, Sarvestani M, Wei X, Yee NK, Senanayake CH (2009) A facile and practical synthesis of $N$-acetyl enamides. J Org Chem 74:9528 and references cited herein

[145] Murugan K, Huang DW, Chien YT, Liu ST (2013) An efficient preparation of Nacetyl enamides catalyzed by $\mathrm{Ru}(\mathrm{II})$ complexes. Tetrahedron 69:268 